\title{
LAS OLIGARQUÍAS URBANAS DE PAMPLONA Y TUDELA EN 1366. DOS COMPORTAMIENTOS DIVERSOS ANTE EL FISCO REAL NAVARRO
}

\author{
JAVIER ZABALO ZABALEGUI
}

\begin{abstract}
SUMARIO
I. La ayuda de 1366 - II. La burguesía de Pamplona ante la ayuda de 1366. - 1. Los jurados y la asignación de cuotas contributivas. - 2. La contribución de las familias de la alta burguesía. - 3. La contribución de la pequeña burguesía. III. La burguesía de Tudela ante la ayuda de 1366. - 1. Sospechas sobre presuntas manipulaciones de cifras. -2 . La contribución por parroquias. -3 . La contribución de las familias destacadas.
\end{abstract}

No es necesario subrayar el interés que para la historia social ofrece el estudio de las oligarquías urbanas en la baja Edad Media. En concreto, el modo y cuantía con que las mismas contribuían al levantamiento de las cargas y tributos -tanto los concejiles como los de la hacienda real- nos permite responder, con mayor o menor detalle según los casos, a estas preguntas: ¿Contribuía la alta burguesía de acuerdo con sus auténticas posibilidades económicas? $\mathrm{O}$, por el contrario, ¿utilizaba su influencia en el municipio para rehuir sus responsabilidades ante el fisco? Si éste último era el caso, ¿de qué modo y, sobre todo, en qué medida lo hacía? '.

1 Entre la bibliografía reciente podemos destacar los trabajos de Denis MENJOT, que ha sabido aprovechar la excepcional información que al respecto proporciona la documentación murciana: Fiscalidad y sociedad. Los murcianos y el impuesto en la baja Edad media, Murcia, 1986; L'élite du pouvoir à Murcie au bas Moyen Age, en «La ciudad hispánica durante los s. XIII al XVI», Univ. Complutense, Madrid 1987, III, pp. 535-566. En el vol. I que bajo el mismo título genérico de «La ciudad hispánica» editó la misma Univ. Complutense en 1985, aparece un estudio de María ASENJO GONZÁLEZ sobre Repartimiento de "pechos* en 
A este respecto, y por lo que se refiere a Navarra, la información contenida en el Libro de fuegos de $1366^{2}$ es prácticamente la única que nos suministra alguna luz, y nos ha servido de base para este trabajo.

En una comunicación presentada al II Congreso General de Historia de Navarra (septiembre de 1990), y que aparecerá en breve en la revista «Príncipe de Viana", llamé la atención sobre el partido que podía sacarse de ese Libro de Fuegos con vistas a dilucidar las citadas cuestiones, y adelanté los datos referentes al comportamiento fiscal de los jurados de Pamplona. En las páginas que siguen he recogido esos datos, pero he ampliado además la encuesta a toda la burguesía de Pamplona y de Tudela, las dos más importantes del reino. Ello nos permite realizar un interesante estudio comparativo de la actitud de ambas oligarquías urbanas -notablemente diverso, según se verá- ante una determinada coyuntura: la ayuda del año 1366.

\section{LA AYUDA DE 1366}

De acuerdo con la práctica que se había hecho habitual desde el comienzo del reinado, Carlos II (1349-87) solicitó una ayuda o contribución extraordinaria por un importe de 40.000 florines '. El motivo alegado por el monarca fue

Tierra de Segovia, pp. 717-744, que se refiere en general a contribuciones recaudadas para subvenir a necesidades del concejo.

Más recientemente, L. Rafael Villegas realiza un minucioso análisis de la fiscalidad de la villa manchega de Chillón, según los datos del patrón municipal de 1525, en «Actas del VI Coloquio Intern. de Historia Medieval Andaluzan, celebrado en 1989 (edit. Univ. de Málaga, 1991, pp. 189-199).

Sobre una importante ciudad castellana, Yolanda GuERRERO NAVARRETE, Fiscalidad regia y poder municipal en Burgos (1453-1476), «En la España Medieval», V, I, Madrid, Univ. Complutense, 1986, pp. 481-499.

En el VI Coloquio Intern. de Historia Medieval Andaluza ya citado, corrió a cargo de A. COllantes DE TERÁn la ponencia sobre Ciudades y fiscalidad, y en el mismo expuso J. Romero Romero El concejo como instrumento de la fiscalidad regia en la Castilla del s. XV Sevilla y los pedidos de Cortes (1406-1474), pp. 161-166.

2 Fue editado, junto con otras piezas semejantes, por J. CARRASCO, La población de Navarra en el s. XIV, Pamplona, 1973, con vistas al estudio de la evolución demográfica del reino.

3 Sobre las ayudas solicitadas por Carlos II, véanse noticias en mi Administración del reino de Navarra en el s. XIV. Pamplona, 1973, pp. 197-207. Sobre ayuda de estos mismos años, P. AZCÁRATE AgUILAR-AMAT, Un ejemplo de contribución extraordinaria en la Navarra del s. XIV: la ayuda del bienio 1364-65, «Espacio, Tiempo y Forma», revista de la Fac. de Geogr. e H.a de la UNED, Madrid, 1989, serie III, 2, p. 13-35; de la misma autora, Notas 
la gran evident necesidat que nos a present avemos por defensión de nuestro regno. La defensa del reino era, en efecto, una de las razones que, según el Fuero General de Navarra, justificaban la imposición de una contribución extraordinaria. Para su recaudación se precisaba la conformidad de los representantes legítimos del reino, reunidos en Cortes Generales. La amenaza sobre la seguridad - defensión del regno- se concretaba en aquellos momentos en las Grandes Compañías, las terribles tropas mercenarias, curtidas en las recientes campañas por tierras francesas, que al mando de Beltrán Duguesclin y otros jefes habían atravesado los Pirineos con el propósito de derrocar a Pedro el Cruel y entronizar a Enrique de Trastámara. Si bien se dirigían a Castilla, aquella turba de feroces guerreros-forajidos no dejó de cometer los previsibles saqueos y atropellos en las comarcas del sur de Navarra, camino de la Rioja ${ }^{4}$, que atravesaron en su marcha. Cabe pensar que si los daños y tropelías no fueron más graves y no afectaron a más localidades del reino fue precisamente gracias al abundante dinero que Carlos II tuvo que repartir entre Duguesclin y los principales capitanes de las Compañías. Dinero que, en último término, procedería de la ayuda a que nos venimos refiriendo.

Al fijar el importe de los 40.000 florines (equivalente a 26.000 libras de carlines, según la cotización entonces vigente de 1 florín $=13$ sueldos), las Cortes y el rey concretaron asimismo los siguientes extremos:

1) La ayuda sería una contribución directa y, según la costumbre, pagadera por familias (fuegos, en la terminología de la época).

2) Contribuirían todos los grupos sociales: no sólo los labradores o

sobre la financiación de la guerra castellano-navarra de 1368 por Carlos II, «En la España Medieval», Estudios en memoria del prof. S. de Moxó, I, Univ. Complutense, 1982, pp. 8397.

4 Según Lacarra, "Cascante, Ablitas, Murchante, Monteagudo, el monasterio de la Oliva y sus granjas habían sido gravemente dañadas por el saqueo. Sólo Corella se libró de las destrucciones" (Historia política del reino de Navarra en la Edad Media, Pamplona, 1973, III, p. 90). Por otras fuentes sabemos que Cortes y Buñuel fueron de las más castigadas por estas bandas de profesionales de la guerra y del saqueo, a los que se calificaba como «almogávares y otras malas gentes que andaban por la Bardena», y por miedo de las cuales apenas se atrevían los navarros a viajar entre Pamplona y Tudela en aquel mes de marzo (J. CarRasCo, La población, p. 577). En mayor o menor medida, toda la comarca o «albara» de Tudela -desde Cadreita y Valtierra hasta Cortes- resultó dañada por las Compañías, tanto a la ida en marzo como a su regreso en agosto de 1366. La información recopilada recientemente por P. AZCÁRATE, El azote de las Compañias y sus estragos en Navarra, «Hispania», 177 (1991), pp. 73-101, se refiere no sólo a los estragos causados por los mercenarios a sueldo de Enrique de Trastámara en 1366, sino también a los provocados -en mucha menor cuantía- al año siguiente por las bandas anglo-gasconas que el Príncipe Negro reclutó en favor del Cruel. 
villanos, los judíos y los moros, sino también los demás estamentos (francos, clérigos e hidalgos).

3) Los cabezas de familia (fuegos) se distribuirían, de acuerdo con su capacidad económica, en cuatro escalones, que pagarían respectivamente 4, 3 , 2 y 1 florín'.

4) Esta distribución en cuatro categorías debería hacerse de tal modo que resultase un promedio de 2 ' 5 florines por familia, tanto a nivel local de cada núcleo de población como a nivel general de todo el reino.

Vale la pena transcribir la orden circular dirigida a cada uno de los recaudadores de las merindades (numero los párrafos para facilitar las referencias):

Karlos, por la gracia de Dios rey de Navarra, conte d'Evreus.

1. A nuestro bien amado recebidor de la merindat de (...), salut. Como por la gran, evident necessidat que nos a present avemos por defensión de nuestro regno, et por otras muchas et diversas maneras et cargas que nos conviene sostener et sostenemos, las quoales buenament a present sostener non podríamos si por los del dicho nuestro pueblo non fuéssemos socorrido.

2. Et por la dicha razón los del dicho nuestro pueblo, como buenos et fieles naturales nos ayan otorgado et dado de su buena voluntad quoaranta mil florines pagaderos a nos, la meytad por todo este present mes d'abril en que estamos, et la otra meatat por el dia et fiesta de Sant Miguel del mes de setiembre primero venient.

3. En tal manera que los dichos florines sean pagados et departidos por fuegos, a saber es en esta forma: Que sean taxados et departidos a los fuego-tenientes en quoatro partes; et que el maor et más podient pague por toda la dicha quoantía otorgada quoatro florines; el más podient empués eill, tres florines; et el meyano, dos florines; et el menor, un florín.

4. Et pora esto taxar, departir et dividir en la forma et manera sobredicha, ayamos ordenado et deputado a vos el sobredicho recebidor comisario en la dicha merindat de (...). Porque fiando de vuestra lealdat et cordura vos cometemos et mandamos que luego sin tarza et otra escussatión inquirades et sepades verdat por vos, o por otro o otros que serán deputados o cometidos por vos, qué et quoántos fuegos lavradores, judíos et moros ha en cada una de las villa, logares et aldeas de la dicha merindat.

5. Et a cada uno de los que terrán los dichos fuegos departades et taxedes, o

SEn la ayuda de 1330 -recaudada como monedaje, para que Felipe de Evreux pudiera acuñar moneda al comenzar su reinado- se establecieron ocho niveles, a los que se asignó respectivamente de uno a ocho sueldos (J. CARRASCO, La población, p. 227 ss., publica la relación de contribuyentes y su cuota respectiva en la uribera» de la merindad de Estella, única que se ha conservado). 
fagades departir et taxar, sobre jura d'aqueillos que en los dichos logares serán o vos sabredes que serán más sabidores de la facultat de las gentes de cada uno de los dichos logares, la quoantía de los dichos florines, departiendo et dividiendo en quoatro florines, al seguient tres, al meyano dos, et al menor uno, segunt dicho es, en manera que respondan uno con otro, segun la taxa sobredicha, a numero de dos florines et medio por cada uno de todo el sobredicho tiempo. Et que la dicha taxación fagades o fagades fazer bien et lealment, sen cubierta, tirada toda favor et afection et volundat.

6. Et el número de los fuegos que de los dichos lavradores, judíos et moros faillaredes en la dicha merindat et bonas villas, et assí bien la taxa et divissión que fecho avredes de los que terrán los dichos fuegos, retengades por roldes seillados so vuestro sieyllo por render aqueillos a nuestro thesorero, escriviendo en el dicho rolde todos los podientes et non podientes, porque con los dichos roldes puedan cuyllir o fazer cuillir en la dicha summa de florines de cada uno, segunt taxado será, dentro en el sobredicho mes.

7. Et a esto fazer, vos damos plenerament nuestras vezes, mandantes por tenor de las presentes a todos nuestros oficialles et súbditos et a quoantos esta nuestra carta verán et hoyrán, que vos obedezcan et fagan por vos, en manera que podades complecer este nuestro mandamiento et comissión. Et esto fazet assí bien et dilligentment, porque a falta vuestra dentro el dicho tiempo non pueda ser detarzada la dicha paga.

8. Data en Esteilla III $^{\circ}$ dia d'abril l'aynno de gracia mil CCC LX seys. Por el seynnor rey en su conseyllo. Ferrando Miranda ${ }^{6}$.

Del contenido de esta circular se deduce, entre otras cosas, que las autoridades conocían previamente y con suficiente aproximación el número de fuegos del reino, los cuales no debían ser menos de 16.000, cifra resultante de dividir los 40.000 florines de la ayuda entre los 2' 5 flor. fijados como promedio global. Es más, sin duda les constaba que el número de familias era algo superior. En efecto, tenían que contar con cierto margen de maniobra, pues bien sabían que -aunque para el promedio de 2'5 florines entraban en cálculo tanto los pudientes como los pobres (podientes et non podientes, dice la circular en el apartado n. ${ }^{\circ} 6$ ) en la práctica, debido a diversas circunstancias, no era posible hacerlo efectivo al cien por cien. De hecho, y según los cálculos realizados por J. Carrasco, el número total de fuegos del reino rondaba los 18.000. Tenemos que suponer, en consecuencia, que la Administración central disponía de un censo reciente, posterior a los años 1361-1362 en los que la mortalidad causada por

- Ver en J. Carrasco, La población, el texto de esta circular, con mínimas variantes en su tenor, dirigida a los recibidores de la Ribera (pp. 411-412), Sangüesa (pp. 447-448), las Montañas (pp. 517-518) y Tierras de Estella (pp. 582-583). 
la segunda oleada de peste había dejado sin validez los recuentos demográficos anteriores .

\section{LA BURGUesía DE PAMPLONA ANTE LA AYUDA DE 1366}

Es bien sabido que, a efectos contributivos como en otros aspectos administrativos, los tres núcleos urbanos de Pamplona -el Burgo de San Saturnino (San Cernin), la Población de San Nicolás, la Navarrería- constituían otras tantas entidades con personalidad propia. El Burgo y la Población tendían a coordinarse entre sí, pero el camino de su progresiva unión no culminaría -tras un serio intento en 1390- sino en 1423, con la incorporación incluso de la Navarrería ${ }^{8}$. Un paso importante en este proceso se había adelantado en 1287 , cuando los diez jurados del Burgo y los diez de la Población decidieron formar una comunidad presidida por los 2 alcaldes y los 20 jurados, procedentes siempre por mitad de cada uno de los dos núcleos urbanos, y renovados anualmente.

Fue a estos magistrados municipales a quienes incumbió la delicada tarea de asignar su cuota -uno, dos, tres o cuatro florines- a cada cabeza de familia, según consta en el encabezamiento del censo de Pamplona ". Esta asignación debía hacerse -como subraya la orden real- con entera lealtad hacia el fisco, sin fraudes ni ocultaciones (bien et lealment, sen cubierta); y, del mismo modo, con equidad respecto de los contribuyentes, sin favoritismos ni agravios comparativos hacia unos u otros (tirada toda favor et afection et volundat) (párr. $n .{ }^{\circ} 5$ de la circular). De lo contrario cargarían su conciencia, pues se les exigía bajo juramento el cumplimiento de estas condiciones.

- Parece lógico suponer que se habría confeccionado un censo para recaudar la ayuda de 1363, que fue de 15 s. por fuego. Las ayudas de 1364 y 1365 se recaudaron asimismo por fuegos, en cuyo caso se pudieron actualizar también entonces los censos (P. AZCÁRATE, Un ejemplo de contribución, pp. 13-35).

' Véase M.' A. IRURITA, El municipio de Pamplona en la Edad Media, Pamplona, 1959. La obra de J. M." LACARRA y A. J. MARTín DuQue, Fueros de Navarra. 2. Pamplona, Pamplona, 1975, incluye una esclarecedora introducción histórica y una excelente selección de documentos que ilustra este lento proceso de acercamiento a lo largo de los ss. XIII y XIV, rematado con la Unión de 1423 . Interesan en especial los doc. n. ${ }^{\circ}$ 50, 77, 86 y 88 . Véase también J. J. MARTINENA, La Pamplona de los burgos y su evolución urbana (s. XII-XVl), Pamplona, 1975.

" "Número de los fuegos del Burgo de Sant Cernin et de la Poblation de Santa Nicollas de Pomplona, et aqueillos taxados por los alcaldes et jurados de la dicha villan (J. CARRASCO, La población, p. 538). 
Como se echa de ver a través de los siguientes Cuadros, los jurados de Pamplona lograron que el promedio de florines por fuego en el conjunto de cada uno de los dos núcleos urbanos (Burgo y Población) coincidiese exactamente con el que establecía la ordenanza real: 2' 5 florines. El promedio de cada calle, sin embargo, osciló bastante: desde un mínimo de 2 hasta un máximo de 3 florines.

\section{CUADRO I}

\section{BURGO DE SAN CERNIN}

\begin{tabular}{|c|c|c|c|c|c|c|}
\hline Fuegos & $1 \mathrm{f}$. & 2 f. & $3 \mathrm{f}$. & $4 \mathrm{fl}$. & $\begin{array}{c}\text { Total } \\
\text { florines }\end{array}$ & $\begin{array}{r}\text { Promedio } \\
\text { flor./fuego }\end{array}$ \\
\hline 1. RÚA MAYOR & & & & & & \\
\hline DE LOS CAMBIOS . . . . . 73 & 14 & 21 & 17 & 21 & 191 & $2^{\prime} 6$ \\
\hline 2. CoRREYERÍA . . . . . 63 & 15 & 25 & 14 & 9 & 143 & $2 \cdot 27$ \\
\hline $\begin{array}{l}\text { 3. PELETERÍA } \ldots \ldots \ldots \ldots 44 \\
\text { 4. TECENDERÍA }\end{array}$ & 12 & 9 & 12 & 11 & 110 & $2 \cdot 5$ \\
\hline VIEJA $\ldots \ldots \ldots \ldots . \ldots 28$ & 4 & 10 & 6 & 8 & 74 & $2 \% 6$ \\
\hline 5. Cotellería $\ldots \ldots \ldots 38$ & 13 & 12 & 8 & 5 & 81 & $2^{\prime} 1$ \\
\hline 6. BURELLERÍA $\ldots \ldots \ldots 80$ & 9 & 40 & 19 & 12 & 194 & $2 \cdot 4$ \\
\hline 7. CARnicería . . . . . . 36 & 1 & 9 & 16 & 10 & 107 & $2 ' 97$ \\
\hline $\begin{array}{l}\text { 8. CARPINTERÍA } \ldots \ldots \ldots 17 \\
\text { 9. RÚAS NUEVAS }\end{array}$ & 2 & 13 & 0 & 2 & 36 & $2 ' 1$ \\
\hline $\begin{array}{l}\text { DEL MERCADO } \ldots \ldots \ldots 49 \\
\text { 10. CAMINO DE }\end{array}$ & 2 & 26 & 14 & 7 & 124 & 2,53 \\
\hline $\begin{array}{l}\text { SAN LÁZARO } \ldots \ldots \ldots 16 \\
\text { 11. CAMINO DE STA. }\end{array}$ & 1 & 5 & 3 & 7 & 48 & 3 \\
\hline [EN]GRACIA $\ldots \ldots \ldots \ldots 8$ & 0 & 0 & 7 & 1 & 25 & $3^{\prime} 1$ \\
\hline TOTAL & 73 & 170 & 116 & 93 & 1.133 & $2 ' 50$ \\
\hline
\end{tabular}


CUADRO II

\section{POBLACIÓN DE SAN Nicolás}

\begin{tabular}{|c|c|c|c|c|c|c|}
\hline Fuegos & $1 \mathrm{f}$ & $2 \mathrm{f}$ & $3 \mathrm{fl}$ & $4 \mathrm{f}$. & $\begin{array}{l}\text { Total } \\
\text { florines }\end{array}$ & $\begin{array}{l}\text { Promedio } \\
\text { por fuego }\end{array}$ \\
\hline 1. Chapitel .......55 & 5 & 17 & 20 & 13 & 151 & 274 \\
\hline 2. TIENDAS $\ldots \ldots \ldots \ldots 18$ & 6 & 2 & 4 & 6 & 46 & 2.55 \\
\hline 3. ZAPATERÍA Y & & & & & & \\
\hline FERRERIA ... & 11 & 14 & 22 & 12 & 153 & 26 \\
\hline 4. TORREDONDA $\ldots \ldots .72$ & 11 & 25 & 24 & 12 & 181 & $2 ' 5$ \\
\hline 5. TECENDERIA . . . . . . 28 & 5 & 8 & 11 & 4 & 70 & $2 \cdot 5$ \\
\hline 6. CARNicERIA .......26 & 5 & 3 & 10 & 8 & 73 & $2^{\prime} 8$ \\
\hline 7. Rún Petita . . . . . . . 23 & 5 & 7 & 7 & 4 & 56 & $2 \cdot 43$ \\
\hline 8. GRANADA . . . . . . 28 & 4 & 21 & 2 & 1 & 56 & 2 \\
\hline 9. Penitencia $\ldots \ldots \ldots 11$ & 3 & 5 & 2 & 1 & 23 & $2^{\prime} 1$ \\
\hline 10. RÚAS NUEVAS $\ldots \ldots \ldots 14$ & 2 & 11 & 0 & 1 & 28 & 2 \\
\hline 11. PARAdís $\ldots \ldots \ldots \ldots 14$ & 3 & 8 & 2 & 1 & 29 & 2 \\
\hline TOTAL 348 & 60 & 121 & 104 & 63 & 866 & $2 \cdot 49$ \\
\hline
\end{tabular}

Las cifras de estos Cuadros sugieren de inmediato algunos comentarios. En primer lugar, la indudable habilidad técnica, desde el punto de vista contable, con la que consiguieron obtener con exactitud -total en el caso de San Cernin, casi total en San Nicolás- el promedio de 2' 5 florines, a partir de promedios tan dispares entre las diferentes calles. ¿Cómo lograron cuadrar las cifras con esta exactitud prácticamente absoluta? Sin duda tuvieron que realizar unos cálculos matemáticos relativamente complejos. Pero más que esa notable pericia en el manejo de los números, la sensación que surge en el ánimo del investigador es la vehemente sospecha de que el logro del promedio exacto de 2'5 flor. se debió obtener a través de algunas manipulaciones fraudulentas de los datos reales, para hacerlos encajar artificialmente con las cifras previstas y deseadas.

Por lo pronto, da la impresión de que las autoridades concejiles optaron por no consignar los nombres de los considerados indigentes (no podientes), que no podían pagar. Evitaron de ese modo que el resto de los contribuyentes tuvieran que suplir con un esfuerzo suplementario el impago de sus convecinos insolventes. De hecho, en la Navarrería nos consta que se produjo una ocultación del verdadero número de vecinos, pues mientras en la lista presentada a los recaudadores de la Hacienda sólo figuran 166 (116 podientes y 50 que no pueden 
pagarnada), por otra referencia sabemos que los fuegos del barrio eran 202. El concejo, en consecuencia, había escamoteado por lo menos 36 fuegos. Ese fraude se lo perdonó Carlos II dos años más tarde ${ }^{10}$. Dado que no se consigna la cuota asignada a cada uno de los vecinos, no podemos utilizar la Navarrería para nuestro análisis principal, pero la existencia comprobada de este fraude -detectado por el descaro, o si prefiere, por la torpeza con que se perpetró- nos hace sospechar fundadamente que también en el Burgo y en la Población pudo darse una mayor o menor ocultación del número real de fuegos, ocultación que sólo porque se realizó con la suficiente habilidad, y tal vez con la complicidad de los funcionarios del fisco real ", no llegó a ser detectada o denunciada.

En otro orden de cosas, en cuanto al promedio de cada calle, causa sorpresa el que se sitúen en la franja más alta -en torno a los 3 florines-rúas como la Carnicería, Camino de San Lázaro y Camino de Santa Engracia (Burgo de San Cernin), donde, por lo que sabemos, no residían con preferencia las familias pudientes. Los apellidos conocidos de la burguesía de S. Cernin se concentraban, por el contrario, en la Rúa Mayor de los Cambios, Correyería, Peletería y Tecendería que, como podemos observar, o no llegan al promedio de 2' 5 o sólo lo superan levemente.

Más en consonancia con el presumible nivel económico de su vecindario parecen contribuir en la Población de San Nicolás. En efecto, la flor y nata de sus negociantes y mercaderes reside en las calles del Chapitel, Tiendas y Zapatería-Ferrería, que globalmente consideradas rebasan -aunque no por mucho, ciertamente- el promedio de 2' 5 florines.

Desde otro punto de vista, puede ser interesante el examen de los porcentajes que representaron cada uno de los cuatro niveles contributivos en el conjunto de cada uno de estos dos núcleos urbanos de Pamplona.

10 J. CARRASCO, La población, p. 549, en particular nota 50, y LACARRA-MARTín DUQUe, Fuero de Pamplona, doc. 79, pp. 253-54. Los oidores de comptos anotan con indudable sorpresa estas anomalías: siendo 202 vecinos, a 2's fl. de promedio debían aportar un total de $505 \mathrm{fl}$. Sin embargo, sólo se han recaudado 290 florines, pues el promedio de 2 ' 5 se ha aplicado no a los 202, ni siquiera a los 166, sino tan sólo a los 116 podientes.

"Es innegable que existían relaciones -de negocio, de amistad, así como de parentesco en algunos casos- entre las familias de la buena burguesía de Pamplona -afincada con preferencia en el Burgo y la Población- y los altos funcionarios de la administración real, como puntualizaremos más adelante (nota 15). No es una temeridad, por consiguiente, sospechar la existencia de un «tráfico de influencias» en este sentido, comparable al descarado favoritismo que desplegaron los jurados para su propio beneficio en la asignación de cuotas de esta ayuda, como comprobaremos enseguida. 


\section{CuAdRo III}

\section{BURGO DE SAN CERNIN}

\begin{tabular}{crrrr} 
Flor. & Fuegus & $\%$ & Florines & $\%$ \\
\hline 1 & 73 & 16,1 & 73 & 6,4 \\
2 & 170 & 37,6 & 340 & 30 \\
3 & 116 & 25,6 & 348 & 30,7 \\
4 & 93 & 20,5 & 372 & 32,8 \\
\hline TOTAL & 452 & & 1.133 & \\
\hline
\end{tabular}

\section{CUADRO IV}

\section{POBLACIÓN DE SAN NiCOLÁS}

\begin{tabular}{crrrr} 
Flor. & Fuegos & $\%$ & Florines & $\%$ \\
\hline 1 & 60 & 17,2 & 60 & 6,9 \\
2 & 121 & 34,8 & 242 & 27,9 \\
3 & 104 & 29,9 & 312 & 36 \\
4 & 63 & 18,1 & 252 & 29,1 \\
\hline TOTAL & 348 & & 866 & \\
\hline
\end{tabular}

Como puede observarse, en el Burgo los niveles de 2, 3 y 4 florines contribuyen cada uno con porcentaje que oscila entre el 30 y el $33 \%$ del total recaudado. En la Población la oscilación es algo mayor (entre el 28 y el $36 \%$ ), mientras que el porcentaje reservado al nivel de 1 florín es sensiblemente parejo en ambos casos ( $\left.6^{\prime} 4-6^{\prime} 9 \%\right)$. Por el momento no estoy en condiciones de averiguar con arreglo a qué criterios o mediante qué cálculos matemáticos se establecieron estos porcentajes ${ }^{12}$. Lo único evidente es que en definitiva los

12 Mucho más sencillo fue el método que se siguió en Sangüesa en esta misma ocasión. En esta localidad los vecinos cristianos -en torno a cuatrocientos- fueron distribuidos en cuatro niveles de igual número de fuegos (cien cada uno, prácticamente). Así se obtenía el promedio de 2,5 fl. con toda facilidad, desde el punto de vista contable. Más adelante examinaremos el caso de Tudela, mucho más complicado que el de Pamplona. 
responsables de ambos barrios lograron presentar a la Hacienda real una cifras perfecramente acordes con el objetivo propuesto: que el total recaudado fuese exactamente el producto de multiplicar 2,5 por el número total de fuegos enumerados en la lista presentada al efecto ".

Pero más que el problema meramente técnico-contable nos interesa en esta ocasión el relativo a los criterios que aplicaron los jurados para asignar a cada vecino su cuota (1-2-3-4 florines). Por desgracia, las fuentes que conocemos no aportan ningún detalle a este respecto. Sólo tenemos constancia de la norma genérica, recordada por la normativa regia (apartado núm. 5 de la circular) de que cada fuego debía contribuir con arreglo a sus posibilidades económicas. Lo que sí sabemos es que la apreciación de las mismas y la consiguiente asignación de cuotas corrió a cargo, en el caso de Pamplona, de los jurados de la ciudad.

\section{Los jurados y la asignación de cuotas contributivas}

Es aquí donde se plantea la cuestión decisiva: ¡actuaron estos jurados con honradez y ecuanimidad? El análisis de los datos disponibles nos proporciona una primera evidencia muy digna de subrayarse: los 2 alcaldes y los 18 jurados (faltan dos en el censo para completar el número legal de 20) se autoasignaron casi por sistema la cuota mínima de 1 florín. Sólo uno de ellos contribuyó con 2 florines, y otro lo hizo con la cuota máxima de 4 florines.

He aquí la nómina de los del Burgo de San Saturnino ${ }^{14}$ y la cuota que se le asignó a cada uno:

En la rúa Mayor de los Cambios:

- el alcalde, Pascual Cruzat (n. $\left.{ }^{\circ} 46\right), 1$ fl. ${ }^{15}$

13 En mi comunicación El reparto de la contribución extraordinaria. El caso de la ayuda de Pamplona de 1366, que aparecerá en la revista «Príncipe de Viana», revisé los datos publicados por J. CARRASCO, La población, p. 538 ss., confrontándolos cuidadosamente con el manuscrito original del siglo XIV. Ello me permitió corregir tanto lecturas de antropónimos como cifras de florines cotizados, así como suplir -y, en su caso, suprimir- algunos contribuyentes que faltaban -o, en su caso, figuraban indebidamente- en la transcripción del editor. No repetiré aquí las correcciones que indico en ese artículo, salvo que afecten a alguno de los vecinos citados expresamente en éste.

${ }_{14}$ Cito para cada uno de ellos el número que les correspondería en la relación de fuegos de su propia calle.

is Pertenece a una familia muy destacada de la burguesía de San Cernin. Se trata de Pascual «el Joven», hijo de Pascual «el Antiguow, nieto de otro Pascual y biznieto de Belenguer Crozat [B. LEROY, Una familia de burgueses de Pamplona en la primera mitad del s. 
En la Correyería:

- Pedro Miguel de Zabalza (n. 3), $1 \mathrm{fl}$.

- Juan de Leyún (n. 29), 1 fl.

En la Peletería:

- Miguel García de Badostáin (n. 24$), 1$ fl. ${ }^{16}$

- Pedro de Lanz (n. $\left.{ }^{\circ} 42\right), 4$ fl.

En la Cuchillería (Cotellería):

- Belenguer de Salt (n. ${ }^{\circ}$ 19), 1 fl.

En la Burellería:

- Ochoa de Ciáurriz (n. 4), 1 fl. "

- Pedro de Guenduláin (n. ${ }^{\circ}$ 59), 1 fl. ${ }^{18}$

En la Carnicería:

- García Miguel de Anoz (n. ${ }^{\circ}$ 1), 1 fl.

Las calles citadas -si exceptuamos la Carnicería- son la residencia preferente de las familias descollantes de la burguesía de San Cernin, y en ellas se concentra también, como vemos, la mayor parte de los jurados. No es preciso insistir en lo significativo de esta coincidencia. dos:

En cuanto a la Población de San Nicolás, véase las cuotas de sus jura-

En la rúa de las Tiendas:

XIV: los Crozat, «Príncipe de Viana», 136-137 (1974), pp. 429-448, con dos cuadros genealógicos]. Este Pascual, alcalde en 1366 y yerno del francés Guillén Auvre -que había sido tesorero del reino hasta 1362-, en agosto de 1375 asesinó a su propia mujer (AGN, Comptos, reg. 153, f. 8 v). Surtía de paños finos a la corte real (B. LEROY, Cartulario del infante Luis de Navarra del año 1361, Pamplona, 1981).

${ }_{16}$ Era cambista y banquero, y se hallaba casado con Catalina de Folcaut, perteneciente a otra destacada familia de la burguesía pamplonesa de la que surgió el obispo Bernardo de Folcaut (J. GoÑI, Los obispos de Pamplona, II, p. 258). Un García de Badostáin será baile de Pamplona en 1368-73.

17 Como puede observarse, hay otros dos Ciárriz en esta misma calle: Aparicio ( $\mathrm{n}$. 71), que paga 1 florín, y Miguel (n. 37$)$, con 4 florines de cuota. Este último es un mercader bastante conocido (M.`C. Grocín, Peaje de Pamplona (1354), «Príncipe de Viana», 182 (1987); J. Zabalo, Peaje de Pamplona (1355), «Príncipe de Viana», 176 (1985), p. 688, núm. 13; del mismo, Peaje de Tudela (1366), «Príncipe de Viana», 187 (1989), p. 357, nota 20). En la Rúa Mayor de los Cambios se encuentran avecindados otros dos Ciáurriz: Guillem (núm. 28), que cotiza 2 fl.; y Juan (n. 54), 3 fl.

${ }_{18}$ Nótese que hay otros tres Guenduláin en esta misma calle: Pedro Sanz de Guenduláin (núm. 66), 3 fl.; Lorenzo de Guenduláin (n..$^{\circ}$ 74), 3 fl.; y Juan Martín de Guenduláin (núm. 78), $1 \mathrm{fl}$. Este último actuaba como corresponsal de mercaderes foráneos en $1355 \mathrm{~J}$. Zabalo, Peaje de Pamplona (1355), ya citado, p. 688, n. $\left.{ }^{\circ} 6\right)$. 
- el alcalde, Miguel Jiménez de Irigoyen (n. $\left.{ }^{\circ} 16\right), 1 \mathrm{fl}$.

- Pedro de Itoiz (n. $\left.{ }^{\circ} 2\right), 1 \mathrm{fl}$.

- Juan de Yábar (n. ${ }^{\circ}$ ), 1 fl.

En la rúa Mayor del Chapitel:

- Guillén de Rosas (n..$^{\circ}$ ), 2 fl. ${ }^{19}$

En la Zapatería y Ferrería:

- Sancho de Munárriz (n. 24), $1 \mathrm{fl}$.

- García de Garbala (n. 44), 1 fl.

En la Torredonda:

- García de Artajo (n. $\left.{ }^{\circ} 71\right), 1$ fl.

- Miguel García de Zalba (n. ${ }^{\circ}$ 72), $1 \mathrm{fl}$.

En la Tecendería:

- García de Roncesvalles (n. $\left.{ }^{\circ} 12\right), 1$ fl. ${ }^{20}$

En la Carnicería:

- Juan de Esnoz (n. $\left.{ }^{\circ} 12\right), 1 \mathrm{fl}$.

En la rúa Petita (Chica) ${ }^{21}$ :

- Sancho de Artica (n. 20$), 1 \mathrm{fl}$.

19 En esta misma calle residen otros dos miembros de la familia: Bertrán de Roses ( Arroses», $n .{ }^{\circ} 9$ ), que contribuye con $3 \mathrm{fl}$. , y maestre Pedro de Rosas ( $n .{ }^{\circ} 4$ ), que lo hace con cuatro. Este linaje de los Rosas, perteneciente a la crema de la burguesía de la Población, dio altos funcionarios a la administración del reino (magistrados, recaudadores, oidores de Comptos, consejeros reales). En 1345, por ejemplo, Esteban de Rosas, licenciado en leyes, era consejero del rey y alcalde del tribunal de la Cort, a pesar de que cinco años antes el almirante de San Nicolás tenía orden de capturar a sus hijos $(J$. ZABalo, La Administración, p. 94, nota 314; IdOATE, Catálogo de Comptos, 51, n. ${ }^{\circ} 41$ ). Nuevos conflictos con la justicia tuvieron miembros de esta estirpe en 1350-51, pues consta que Beltrán, Juan de Rosas y otros familiares fueron condenados al pago de mil libras, acusados -junto con Pedro Cruzat- de la muerte del mercader Martín de Esparza (IDOATE, Cat. Comptos, 51, n..$^{\circ}$ 621). A pesar de estos problemas no perdieron la confianza de Carlos II y de Carlos III: Pedro de Rosas fue recibidor de la merindad de Sangüesa (1355-61); y Guillén de Rosas, después de serlo de la de Estalla (1370-73), actuó como oidor de Comptos y alcalde del mercado de Pamplona (J. ZABALO, La administración, notas 282, 441,442, 1227; J. GOÑI, La formación intelectual de los navarros en la Edad Media, "EEMCA", X, doc. 136). Los Rosas emparentaron con los Cruzat, enlazados a su vez con los Eza (B. LEROY, Una familia de burgueses, «Príncipe de Viana», 1974, p. 431).

${ }^{20}$ No sabemos si el conocido comerciante de ese nombre se identifica con este jurado o con el homónimo residente en la Zapatería y Ferrería (n..$^{\circ}$ 3). En asociación con otros comerciantes, García de Roncesvalles tuvo en arriendo el año 1368 la imposición del reino, y surtía de paños bordados en oro a la capilla real (J. ZABALO, Peaje de Tudela de 1365, Universidad de Navarra, Pamplona 1973, nota 28).

21 Transcrita como «Penta» por el editor. 
¿Reflejaban estas cuotas -casi por sistema las más bajas- la verdadera situación económica de las jurados?' A la vista de los datos que hemos venido citando en las notas, y sabiendo que, según la normativa vigente desde hacía tiempo, debían pertenecer a la categoría de los «buenos hombres», es decir, los de posición desahogada, la respuesta no puede ser afirmativa. El cargo de jurado era anual, pero los salientes nombraban a los entrantes y, aunque debían jurar que no harían la designación per ben volenfa nin per mal volenf̧a, nin per amiztat nin per parentesc, nin per esperança que hayan ad averdann nin pro ${ }^{22}$, hay que sospechar que se desarrolló entre ellos un indudable espíritu corporativo.

En definitiva, parece innegable que nos hallamos ante un caso evidente de descarado autofavoritismo entre los jurados pamploneses, que aprovecharon impunemente su intervención en el engranaje de la administración fiscal para rehuir en gran medida sus deberes cívicos ante la Hacienda regia. Todo ello, por cierto, en flagrante contradicción con el espíritu y la letra de la ordenanza oficial, que obligaba a cada uno a contribuir con arreglo a sus auténticos recur$\operatorname{sos}^{23}$.

\section{La contribución de las familias de la alta burguesía}

Examinado el caso de las autoridades concejiles (alcaldes y jurados) podemos ampliar la encuesta y tratar de averiguar cómo se comportaron en esta misma ayuda las familias presuntamente más adineradas de Pamplona; ¿contribuyeron sistemáticamente con la cuota máxima de 4 florines?.

He seleccionado los apellidos que -a juzgar por la información disponiblepueden ser clasificados como miembros de la alta burguesía de los negocios, es decir, la oligarquía urbana pamplonesa.

Véase el cuadro resultante:

22 M." A. IRURITA, El municipio de Pamplona, p. 67, citando el acuerdo de 1287. Para impedir el monopolio de los cargos por las personas influyentes, ese mismo acuerdo dispone que los jurados no podían ser reelegidos hasta pasados siete años.

${ }^{23}$ Ciertamente, en este aspecto el caso de Pamplona es uno más dentro de la tendencia general que se observa en las ciudades bajomedievales, como vienen poniendo de relieve las investigaciones. 


\title{
CUADRO V
}

\author{
BURGO DE S. CERNIN
}

1 f. 2 f. 3 f. 4 ค. $\begin{gathered}\text { Total } \\ \text { Fuegos }\end{gathered} \begin{gathered}\text { Total } \\ \text { Florines }\end{gathered} \begin{gathered}\text { Promedio } \\ \text { flor. } / \text { fuego }\end{gathered}$

\begin{tabular}{|c|c|c|c|c|c|c|c|}
\hline CRUZAT ${ }^{24}$ & 1 & 3 & 2 & - & 6 & 13 & $2 \cdot 16$ \\
\hline EZA $"$. & 1 & - & - & 1 & 2 & 5 & 2.5 \\
\hline FOLCAUT ${ }^{26}$ & - & - & - & 1 & 1 & 4 & 4 \\
\hline JURDAN ${ }^{2 ?} \ldots$ & 2 & - & - & - & 2 & 2 & 1 \\
\hline PEREZ DE ESPARZA $^{28} \ldots$ & - & - & 1 & 2 & 3 & 11 & 3.6 \\
\hline
\end{tabular}

24 Además del Pascual Cruzat, alcalde ya citado (nota 15), hay una Bona Cruzat en la Correyería (n. ${ }^{\circ} 22$ ), que paga 2 fl., la misma cuota que Juan Cruzat el Mayor en la Peletería (n. ${ }^{\circ}$ ), mientras que cotizan $3 \mathrm{fl}$. otro Juan Cruzat y el Miguel Cruzat de esta misma calle (n. 3 y 11). Hay que advertir que en la edición se hallan erróneamente duplicados "Martín Jurdan cambiador" -no confundirlo con el que encabeza la lista- "Johan de Ronçavals» y "Miguel Crozat». Sobre el parentesco de los Cruzat con los Rosas, los Roncesvalles y los Caritat, ver el art. de B. LEROY, Una familia de burgueses, ya citado.

2) Con cuatro fl. cotiza Artal de Eza, avecindado en la Tecendería Vieja (n. $\left.{ }^{\circ} 24\right)$. Este conocido cambista y banquero, emparentado con los Cruzat -estaba casado con Anglesa Cruzat-había sido almirante del Burgo (1347-51) (IDOATE, Cat. Comptos, 51, n. 569 y 638; J. CARRASCO, La población, p. 406; mi Administración, p. 147, nota 558, y J. GoÑI, Los obispos, II, s. v. «Deza»). Nótese que su pariente Belenguer de Eza, vecino de la Correyería (n. $\left.{ }^{\circ} 19\right)$, contribuye sólo con 1 florín. Elías de Eza, arcediano de Berberigo, fue recibidor de la Ribera en 1359, y de la merindad de Sangüesa en 1363 J. ZABALO, La administración, p. 152; Comptos, reg. 107, f. 123). Tal vez se pueda leer como Eza el García de Iza que había prestado cien libras al gobernador en 1361 (B. LEROY, Cartul. infante Luis, doc. 121).

${ }^{26}$ Sólo aparece citado Guillem Folcaut, vecino de la Correyería (núm. 31), seguramente pariente del por entonces obispo de la diócesis, Bernat Folcaut (1364-77) U. GoÑI, Los obispos, II, p. 229). Hay que advertir que realmente desembolsó 4 florines, y no los 3 que indica en nota el editor. Recuérdese que con una Catalina Folcaut casó el jurado y banquero Miguel García de Badostáin (nota 16).

${ }^{27}$ Sólo 1 florín pagan los dos Martín Jurdán, avecindados en la Peletería ( $n .^{\circ} 1$ y 6). Ya hemos advertido anteriormente que se halla repetido por error en la edición el «Martín Jurdan cambiador». Sobre las actividades de esta familia de cambistas-banqueros, ver mi Administración, índice de nombres, s. v. "Jurdan», y B. LEROY, Cartul. infante Luis, p. 36.

${ }^{28}$ Con cuatro florines contribuyen dos miembros de este linaje: Juan Pérez de Esparza, vecino de la Tecendería Vieja (.$^{\circ}{ }^{11}$ ), que fue notario de la Cort y luego alcalde del mismo tribunal (CASTRO, Catálogo Comptos, II, n. ${ }^{\circ} 665$ y 888; B. LEROY, Cartul. infante Luis, índice de nombres) y Guillén Pérez de Esparza, en la Rúa Mayor de los Cambios (n. 11), al que se atribuyen erróneamente $3 \mathrm{fl}$. en la edición. En esta misma rúa aparece un Miguel Pérez de 


1 ค. 2 ค. 3 f. 4 f. $\begin{gathered}\text { Total } \\ \text { Fuegos }\end{gathered} \begin{gathered}\text { Total } \\ \text { Florines }\end{gathered} \begin{gathered}\text { Promedio } \\ \text { flor./fuego }\end{gathered}$

\begin{tabular}{lllllllll} 
RONCESVALLES $^{24} \ldots \ldots \ldots$ & - & - & - & 2 & 2 & 8 & 4 \\
UNDIANO $^{30} \ldots \ldots \ldots \ldots$ & - & 1 & - & 1 & 2 & 6 & 3 \\
ZALBA $^{* 11} \ldots \ldots \ldots \ldots$ & - & - & - & 2 & 2 & 8 & 4 \\
\hline TOTAL & 4 & 4 & 3 & 9 & 20 & 57 & 2.85
\end{tabular}

POBLACIÓN DE S. NiCOLÁS

\begin{tabular}{llllllll} 
& 1 ค. & 2 ค. & 3 ค. & 4 f. & $\begin{array}{c}\text { Total } \\
\text { Fuegos }\end{array}$ & $\begin{array}{c}\text { Total } \\
\text { Florines }\end{array}$ & $\begin{array}{c}\text { Promedio } \\
\text { flor./fuego }\end{array}$ \\
\hline $\operatorname{MOZA}^{32} \ldots \ldots \ldots \ldots \ldots$ & - & - & - & 2 & 2 & 8 & 4
\end{tabular}

Esparza tasado en 3 florines ( $n .^{\circ}$ 63). Ver más noticias sobre este linaje en mi Administración de Navarra, índice de nombres.

29 Reconozco que carezco de datos positivos para asignar a este destacado linaje de comerciantes los dos que pagan 4 florines: Juan, avecindado en la Peletería ( $\left.n .^{\circ} 4\right)$, y la mujer de Domingo de Roncesvalles, en la Carnicería (.$^{\circ}{ }^{6}$ ). Quedaría rebajado el promedio si suponemos miembros de esta estirpe al Martín de Roncesvalles, tasado en 2 fl. en la Correyería ( $n .^{\circ}$ 59), y al Domingo de Roncesvalles que paga 1 florín en la Burellería (n. ${ }^{\circ}$ 65). Sobre los Roncesvalles, ver noticias en C. ORCÁSTEGUI, La crónica de Garci López de Roncesvalles, Pamplona 1977, pp. 12-14 y mi Peaje de Tudela de 1365, ya citado. Adviértase que hay otros Roncesvalles avecindados en la Población de San Nicolás.

10 Juan de Undiano, vecino de la rúa Mayor de los Cambios (n. ${ }^{\circ} 32$ ), aparece tasado en 4 florines, mientras que un homónimo de la Peletería (núm. 14) lo está sólo en 2 fl. Otros tres Undianos se encuentran en la Población, como veremos. Por supuesto, no sabemos si todos ellos pertenecen al mismo linaje. Recordemos que a comienzos de siglo un Ochoa Martínez de Undiano había casado con Anglesa Cruzat (B. LEROY, Una familia de burgueses, p. 435).

${ }^{31}$ He supuesto que serían miembros de la familia burguesa - de la cual salieron sendos obispos de Pamplona, años más tarde- tanto el Juan de Zalba como el Eneco de Zalba que cotizan $4 \mathrm{fl}$. en la Burellería ( ${ }^{\circ}{ }^{\circ} 5$ y 6 ). Este último actuaba en 1358 como corresponsal de mercaderes foráneos (J. CARRASCO, El peaje de Pamplona de 1358, "Cuadernos de Estudios Medievales», VIII-IX, Granada, 1983, p. 121) y en 1371 participó con otros mercaderes en el arriendo de la alcabala de Pamplona y las Montañas (nota 33).

${ }_{12}$ Ambos miembros de este relevante linaje burgués contribuyeron con 4 florines: Pascual Moza, primero de la lista en la Rúa Mayor del Chapitel; y Juan Moza, en las Tiendas (n. $\left.{ }^{\circ} 12\right)$. El primero sirvió a Carlos II y Carlos III como recibidor de las Montañas en 1386, oidor de Comptos y consejero real más tarde. Ya en 1381 vendía al monarca 6 marcos de 


1 ค. 2 ก. 3 f. 4 ก. $\begin{gathered}\text { Total } \\ \text { Fuegos }\end{gathered} \begin{gathered}\text { Toral } \\ \text { Florines }\end{gathered} \begin{gathered}\text { Promedio } \\ \text { flor./fuego }\end{gathered}$

\begin{tabular}{lllllllll} 
RONCESVALLES & $\ldots \ldots$ & 2 & - & 2 & 1 & 5 & 12 & 2.4 \\
ROSAS & $\ldots \ldots \ldots \ldots \ldots$ & - & 1 & 1 & 1 & 3 & 9 & 3 \\
UNDIANO ${ }^{\prime \prime} \ldots \ldots \ldots \ldots$ & - & - & - & 3 & 3 & 12 & 4 \\
\hline TOTAL & 2 & 1 & 3 & 7 & 13 & 41 & 3.15 \\
\hline
\end{tabular}

Total estas familias de los

$\begin{array}{llllllll}\text { dos burgos } & 6 & 5 & 6 & 16 & 33 & 98 & 2^{\prime} 97 \text { flor. }\end{array}$

plata (J. ZABALO, La administración, p. 83, nota 239; p. 112, 126 y 152). Su hija María casó con Garci López de Roncesvalles, también burgués de la Población y alto funcionario de la Administración real, que suplió en 1386 como recibidor de las Montañas a su suegro, y llegó a ser Tesorero real desde 1403 hasta su fallecimiento en 1437 (C. ORCÁSTEGUI, Crónica de Garci López de Roncesvalles, pp. 11-14). En 1361 Pascual Moza, hijo de Juan Moza, recibióla salvaguarda del gobernador para que no pudiera ser prendido ni embargado (B. LEROY, Cartul. infante Luis, doc. 7).

"Con 4 florines contribuye Nicolás de Roncesvalles, vecino de la rúa del Chapitel (n. ${ }^{\circ}$ 45). Este hombre de negocios actuaba ya como recaudador de la ayuda de la Población de San Nicolás en 1364 en compañía del cambista Ochoa de Undiano, a su vez avecindado en las Tiendas de la Población. En asociación con Pedro Palmer -convecino del Chapitel (n. ${ }^{\circ}$ 43) que paga $4 \mathrm{fl}$. en esta ayuda- había prestado a Carlos II ciento veinte libras antes de julio de 1369. Nicolás de Roncesvalles aparece asociado también en 1371 con Eneco de Zalba en el arriendo de impuestos. Se dedicaba a la importación de pescado, aceite y paños (U. ZABALO, Peaje de Tudela de 1365, Universidad de Navarra, Pamplona 1973, p. 92, nota 27; Peaje de Tudela de 1366, ya citado, p. 357).

En 3 florines están tasados Lope de Roncesvalles, vecino del Chapitel (n. 36 ), y García de Roncesvalles, vecino de la Zapatería y Ferrería (n..$^{\circ}$ ). No sabemos si debe identificarse con éste último, o con su homónimo de la Tecendería de la Población (n. $\left.{ }^{\circ} 12\right)$, el jurado García de Roncesvalles, que está documentado como destacado negociante en estos años (nota 20).

La cuota mínima de 1 florín se asignó a Esteban de Roncesvalles, vecino de la rúa Petita (n. ${ }^{\circ}$ ), que actuaba frecuentemente como corresponsal de mercaderes foráneos (A. J. MARTín DuQue, Peaje de Pamplona de 1351, Universidad de Navarra, 1973, p. 26, n. ${ }^{\circ}$; M." $^{.}$ C. Grocin, Peaje de Pamplona de 1354, ya citado, p. 807, n.॰ 20; J. ZABalo, Peaje de Pamplona de 1355, citado, p. 688, n..$^{\circ}$. No se le debe confundir con el homónimo vecino de Bayona (J. LLansó, Peaje de Pamplona de 1362, «Príncipe de Viana», 181 (1987), p. 366. n. 141).

'4 En la nota 19 hemos dado noticia de este linaje burgués, avencindado en la rúa Mayor del Chapitel de la Población. ¿Descenderían del lugar de St. Martín d'Arrossa, cercano a Osses, en la castellanía de S. Juan de Pie de Puerto?

is Aunque se registran otros dos Undiano en el Burgo de S. Cernin (nota 30), parece 
Como ya hemos advertido oportunamente más arriba, ciertamente no podemos asegurar que todos los apellidos homónimos pertenezcan a los mismos linajes aquí consignados. Pero, aun teniendo en cuenta estas salvedades, las cifras del Cuadro precedente parecen bastante demostrativas. Como vemos, el promedio de estos 33 fuegos -equivalente al $4 \%$ del censo de los dos núcleos urbanos de Pamplona- no supera los 3 florines. Especialmente llamativo es el caso de los seis Cruzat, del Burgo de San Cernin, cuyo promedio apenas rebasa los 2 florines; por no hablar de los dos Jurdán, que cotizan la cifra mínima de 1 florín. Otros linajes (Eza, Roncesvalles) se sitúan simplemente en la media de 2 ' 5 prevista para el conjunto de los vecinos del reino.

Y, para hacernos una idea del poder adquisitivo del florín por esas fechas, recordemos que equivalía a 13 sueldos carlines, y que 2 sueldos y 4 dineros era el jornal diario de un trabajador de tipo medio (albañil, carpintero, etc.). De modo que 1 florín venía a ser el salario semanal de un trabajador corriente.

\section{La contribución de la pequeña burguesía}

Precisamente por su más escasa relevancia social y económica, los miembros de la que catalogaríamos como burguesía media o pequeña nos son menos conocidos que los de la alta burguesía pues, si bien formaban un sector más numeroso que ésta, han dejado en la documentación una huella más leve y borrosa.

Sólo gracias, principalmente, a las cuentas de algunos pocos peajes de mediados del siglo XIV que por fortuna han llegado hasta nosotros, podemos reunir alguna información complementaria sobre 21 pequeños burgueses

que los principales representantes de esta destacada familia burguesa residen en San Nicolás. Dos de ellos, en la Rúa de las Tiendas: Ochoa de Undiano y Miguel de Undiano ( $n .^{\circ} 14$ y 150 , tasados ambos en 4 florines. Ochoa de Undiano era un activo negociante, que actuaba a veces asociado con su convecino de la rúa del Chapitel, Nicolás de Roncesvalles (nota 33), o con los Cruzat. Junto con Miguel Cruzat, por ejemplo, era acreedor, por valor de más de 600 libras, del judío Ezmel de Ablitas, nieto del homónimo y famoso prestamista (B. LEROY, Recherches sur les juifs de Navarre à la fin du Moyen Age, REJ, julio-diciembre 1981, p.394; de la misma, Cartul. del infante Luis, p. 150) Véase también mi Peaje de Pamplona (1355), p. 688, n..$^{\circ}$. No me consta -aunque así lo he supuesto- que al mismo linaje pertenezca el Juan de Undiano vecino de la Torredonda (n. $\left.{ }^{\circ} 44\right)$ y tasado en 4 florines. 
-comerciantes, en general- citados en el Libro de Fuegos de 1366 en el Burgo y la Población de Pamplona.

En cuatro florines -con las salvedades que luego indicaremos- aparecen tasados 16 de ellos; en tres florines, 1; en dos florines, los 4 restantes.

De los tasados en cuatro florines, 10 se hallan avecindados en el Burgo de San Cernin: son los comerciantes Miguel de Gascue "6 Miguel de Meoz ", Pedro Alamán ", Juan Bertrán, que había sido alcalde de San Cernin en 1361 ", Miguel Laguiller o l'Aguillor ${ }^{40}$, el francés Colin le Lievre, clérigo del Tesorero y oidor de la Cámara de Comptos ${ }^{41}$, el comerciante y médico real Peru Ezquerra ${ }^{42}$,

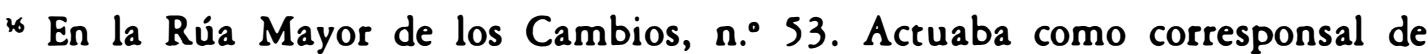
comerciantes foráneos en 1351, 1354 y 1355, según los peajes de Pamplona de esos mismos años, y como mercader por cuenta propia en 1363 (J. Fr. ElizArI, Peaje de Lecumberri de 1363, Memoria de Licenciatura inédita, p. 43) liquidando 20 s. Hay que suponer que -lo mismo que los demás corresponsales pamploneses citados en las siguientes notas- actuaba frecuentemente por cuenta propia, y si no figura en los registros de los peajes se debe a que los burgueses de Pamplona habían logrado por entonces la exención de ese impuesto.

"En la Rúa Mayor de los Cambios, n. ${ }^{\circ}$ 44. El editor le atribuye erróneamente una cuota de 3 florines. Liquidó 49 s. en el peaje de Lecumberri del año 1363 (ver nota anterior) y también se le cita en el de Pamplona de 1351.

* En la Correyería, n. ${ }^{\circ}$. Me atrevo a suponerlo pariente del Miguel Alamán, documentado como corresponsal de mercaderes foráneos en los Peajes de Pamplona de 1351 (p. 26), de 1355 (p. 688, núm. 9) y de 1358 (J. CarrasCo, en "Cuad. de Est. Mediev.», 8-9, Univ. de Granada), y atestiguado como alcalde de Cort en 1356 (J. ZABALO, La administración, p. 278, nota 1177).

"B. LeROY, Cartul. del infante Luis. En la Peletería, n. 18. Un Miguel Bertrán figura como corresponsal de mercaderes foráneos en 1358 (J. Carrasco, Peaje de Pamplona de 1358, citado, p. 121).

* En la Peletería, n. ${ }^{\circ} 33$. Se halla documentado como el comerciante más destacado -liquida 660 s.- en el peaje de Lecumberri de 1363 (J. Fr. ELIZARI, memoria inédita ya citada, p. 42 y 52). Se especializaba en el comercio de paños, de los que surtía a la corte real (B. LEROY, Cartul. del infante Luis, transcrito "Laguiller").

"Aunque tasado en 4 florines, no llegó a pagar nada (J. CARrasco, La población, p. 572), como tampoco su vecino Ochoa de Saldías, ambos habitantes en la Tecendería Vieja (n. 12 y 13). Nicolás (Colín) le Lievre, de origen francés, fue clérigo del Tesorero (1350-65), y oidor de Comptos a continuación, al menos hasta 1382 (J. ZABALO, La administración, índice de nombres; J. CARRASCO, La población, pp. 515 y 516 ).

${ }^{2}$ En la Cuchillería, n. ${ }^{\circ}$ 18. Actuó como físico o médico de Carlos II (J. Zabalo, Participación navarra en la guerra de los 2 Pedros (1362-1363), «Actas del I Congreso General de Historia de Navarra, Comunicaciones de Edad Media», p. 687, nota 15), pero también comerciaba con aceite en 1355 J. ZABalo, Peaje de Pamplona de 1355, citado, p. 687, n. ${ }^{\circ}$ 52). 
y los comerciantes Miguel de Ciáurriz ", Bartolomé de Navaz ${ }^{44}$ y Juan de $\mathrm{Meoz}$ ".

Los otros seis tasados en 4 florines residen en la Población de San Nicolás. Son el funcionario de la Cort y de la Cámara de Comptos, don García Pérez de Aranguren ${ }^{*}$, y los mercaderes Martín de Alviz ${ }^{4}$, Jimeno de Burlada ${ }^{48}$, Pedro Palmer ", Miguel Martínez de Reta ${ }^{\text {*0 }}$ y Jimeno de Larrángoz".

El único tasado en 3 florines es Juan López de Zariquiegui, perteneciente a una familia de almirantes de la Población de San Nicolás".

De los que pagaron 2 florines sólo uno es vecino de San Nicolás: el comerciante Martín de Echalecu ". Los otros tres residen en San Cernin: son los

4" En la Burellería, n. 37. Véase lo dicho sobre los Ciáurriz en la nota 17.

44 En la Burellería, n. 26. Liquidó 20 s. en el peaje de Lecumberri de 1363 J. Fr. ELIZARI, memoria citada, p. 43).

45 En las Rúas Nuevas del Mercado, n. ${ }^{\circ} 10$. Liquidó 110 s. en el peaje de Lecumberri de 1363, en el que se especializó en la importación de arenques (J. Fr. ELIZARI, memoria citada, p. 42).

${ }_{46}$ En el Chapitel, $n .{ }^{\circ} 29$. Este notario del tribunal de la Cort y encargado de oir cuentas (J. ZABALO, La administración, p. 123, 127, 128, 139, 280; B. LEROY, Cartul del infante Luis) en realidad no pagó los 4 florines en que fue tasado (J. CARRASCO, La población, p. 572).

47 En la misma rúa del Chapitel, n. ${ }^{\circ}$ 13. Documentado como mercader (J. ZABALO, Peaje de Tudela de 1366), sabemos que prestó 80 libras al rey en 1369 (P. AzCÁRATE, Notas sobre la financiación -citada en nota 3-p. 91).

${ }_{48}$ "Xemeno de Bruslada", vecino del Chapitel, n. 42, destacado comerciante, muy relacionado con el puerto de Bayona (A. J. MARTÍn DUQUE, Peajes navarros. Vera y Lesaca (1358-59), "Homenaje a J. E. Uranga", Pamplona, 1971, p. 79; el mismo, Peaje de Pamplona (1351), Universidad de Navarra, Pamplona, 1973, pp. 25-27).

49 Véase noticia sobre este comerciante -que actuaba asociado con su convecino de la Población, Nicolás de Roncesvalles- en nota 33.

"En la Torredonda, n. ${ }^{\circ} 37$. Liquidó la modesta suma de $24 \mathrm{~s}$. en el peaje de Lecumberri de 1363 (J. Fr. ElizARI, memoria citada, p. 43).

"En la Carnicería, n. ${ }^{\circ}$ 7. Aparece documentado como corresponsal de mercaderes foráneos en J. ZABALO, Peaje de Pamplona de 1355, p. 688, n. ${ }^{\circ}$ 28, y M.' C. GroCin, Peaje de Pamplona de 1354, p. 806, n. 2.

32 En la Zapatería y Ferrería, n. ${ }^{\circ} 24$. Pertenece a una familia de cierto relieve, pues un Jimeno López de Zariquiegui había sido almirante de la Población recientemente (136264). Tal vez era pariente también el Pérez de Zariquiegui que había desempeñado ese mismo cargo municipal en 1349 (IDOATE, Cat. Comptos, 51, n. ${ }^{\circ}$ 631) y el Lope Pérez de Zariquiegui, baile de los judíos de Pamplona en 1352-53 y 1355-56.

"En la rúa Petita, n. ${ }^{\circ}$ 21. Era agente de comerciantes foráneos (A. MARTín DUQUE, Peaje de Pamplona de 1351, ya citado, p. 26, n. 9; M.' C. Grocín, Peaje de Pamplona de 1354, p. 806, n. ${ }^{\circ} 19$; J. ZaBalo, Peaje de Pamplona de 1355, p. 688, n. ${ }^{\circ} 4$ ). Supongo que se le puede identificar con el Martín Miguel de Echalecu, hotelero de Pamplona (B. LEROY, Cartul. infante Luis, doc, 148). 
comerciantes Lorenzo de Sorauren ", Pedro Robín "y Miguel de Aldaregui ".

Como se deduce de estos datos, los que hemos calificado de pequeños o medianos burgueses tuvieron que contribuir como promedio en mayor grado que los grandes burgueses, pues mientras éstos últimos no superan en conjunto los 3 florines, a aquéllos se les asigna más frecuentemente la cuota de 4 florines. Acabamos de comprobar, por otra parte, que los situados en las esferas de la Administración Central -casos de Colin le Lievre (oidor de Comptos) y García Pérez de Aranguren (notario de la Cort)- logran eludir por completo el pago de la ayuda (notas 41 y 46).

En definitiva, parece posible concluir que las familias más pudientes, los componentes del patriciado urbano -por emplear una expresión consagrada que tal vez puede resultar un tanto grandilocuente aplicada a la Pamplona del siglo XIV-, se mostraron extremadamente reacios a contribuir a la ayuda de 1366. Podemos decir, en consecuencia, que incumplieron sus deberes fiscales -en algunos casos, de manera escandalosa - no sólo desde el punto de vista ético sino también desde el estrictamente legal, ya que infringieron la normativa regia que obligaba a cada uno a contribuir de acuerdo con su capacidad económica.

Es lástima que, aparte de la de 1366, no dispongamos de listas de contribuyentes de Pamplona - con sus respectivas cuotas- para otras fechas próximas. Hay que esperar sesenta años, prácticamente dos generaciones, para encontrar en el Libro de fuegos de 1427 un texto equivalente al que aquí venimos analizando. Una distancia cronológica excesiva, pues hay que suponer que el vecindario se había renovado profundamente en el tiempo intermedio, afectado por sucesivas y mortales oleadas de peste ".

Por lo que se refiere a otros centros urbanos de Navarra, no podemos

${ }^{4}$ En la Rúa Mayor de los Cambios, n. ${ }^{\circ}$. Actuaba por cuenta de mercaderes foráneos (Peaje de Pamplona de 1351, p. 26, n. ${ }^{\circ}$ 14; Peaje de Pamplona de 1355, p. 688, n. ${ }^{\circ}$ 14; Peaje de Pamplona de 1362, p. 361), y por cuenta propia, liquidando 37 s. en el Peaje de Pamplona de 1354, pp. 805 y 806.

"También vecino de la Rúa Mayor de los Cambios, $n .{ }^{\circ} 45$. Actuaba como corresponsal de mercaderes forasteros en el Peaje de Pamplona de 1354, p. 806, n. ${ }^{\circ} 13$, y en el de 1355 (p. 688, n. 3).

${ }_{56}$ Vecino de la Carnicería, núm. 20. Documentado también como agente de mercaderes forasteros en el Peaje de Pamplona de 1351, p. 26, n. ${ }^{\circ} 13$.

"No descarto, de todos modos, el acometer más adelante el análisis de este padrón de 1427. Hasta no haberlo realizado no podemos adelantar el interés de sus conclusiones y hasta qué punto será posible un estudio comparativo con el de 1366. En un primer examen parece que las cuotas normales oscilaron en proporción de uno a cinco (de 8 a 40 s., aunque hay viudas que pagan $4 \mathrm{e}$ incluso $2 \mathrm{~s}$., y «mozos soldaderos» que cotizan de 4 a $8 \mathrm{~s}$.). Por entonces el florín equivalía a 30 sueldos carlines. 
establecer comparaciones con Sangüesa ni con Estella. Con aquélla, porque su burguesía era de muy pequeña entidad y, correlativamente, apenas documentada en sus familias concretas ". Con Estella -cuya burguesía es algo más destacada y conocida-porque el censo de 1366 no indica la cuota asignada a cada vecino, y sólo nos consta que pagaron globalmente, entre podientes y nopodientes, el promedio de 2'5 florines por fuego".

En cambio, sí que podemos hacer un estudio comparativo con Tudela, que contaba con una numerosa burguesía, activa y relativamente bien documentada, y cuyo censo de 1366 especifica la cantidad de florines con que se tasó a cada vecino.

\section{LA BURGUESÍA DE TUDELA ANTE LA AYUDA DE 1366}

La nómina de los fuegos cristianos de Tudela que cotizaron en la ayuda de 1366 aparece distribuida en las diez parroquias de la localidad ${ }^{60}$. Es ésta una primera diferencia formal respecto de Pamplona -cuyo censo se distribuye por calles- pero hay otras diferencias más importantes, no simplemente formales, como vamos a ver.

En primer lugar sorprende el encabezamiento del texto, que reza así: Copia dada a los fuegos de Tudela por los IIII florines por fuego. Como ya sabemos, el promedio fijado para cada población y para todo el reino era de 2'5, y los 4 florines era sólo el más alto de los cuatro tramos previstos. Esta sorpresa queda confirmada cuando comprobamos que, de hecho, el promedio pretendido y «logrado» -enseguida comentaremos este extremo- es efectivamente de 4 florines por fuego ${ }^{61}$.

38 Véanse algunas noticias en J. CARRASCO, Aproximación al mercado monetario de las villas navarras del Camino de Santiago: Sangïesa (1362-64), AEM, 18, pp. 337-347.

"La lista de fuegos está publicada por J. CARRASCO, La población, p. 582 ss.

${ }^{60} \mathrm{~J}$. Carrasco, La población, p. 439 ss. Como en el caso de Pamplona, esta transcripción la hemos cotejado cuidadosamente con el ms. original, lo cual nos ha permitido enmendar algunas lecturas del editor, tanto de los antropónimos como de las cifras de florines, según iremos advirtiendo oportunamente. Por supuesto, he dejado de lado los judíos y moros -muy numerosos en Tudela- y me he ceñido a la población cristiana. Sobre las parroquias y su localización, con un plano de la Tudela medieval, véase C. ORCASTEGUI, Tudela durante los reinados de Sancho el Fuerte y Teobaldo I, «EEMCA», X (1975).

61 También en Tafalla -donde las cuotas oscilan entre 1 y $12 \mathrm{fl}$.- el promedio «logrado» es de $4 \mathrm{fl}$. por fuego, tanto entre los 120 vecinos «labradores» como entre los 18 «hidalgos». En Artajona el promedio es de $3 \mathrm{fl}$. por fuego, si bien parece referirse al año 1368 (J. Carrasco, La población, pp. 435-436). Pero estos casos parecen bastante excepcionales, y 
Veamos las cifras:

\section{CUADRO VI}

\begin{tabular}{|c|c|c|c|c|c|c|}
\hline Parroquias & $\begin{array}{c}\begin{array}{c}\text { Fuegos } \\
\text { normales }\end{array} \\
\end{array}$ & Florines & Promedio & $\begin{array}{l}\text { Flor. de peguja- } \\
\text { leros y pupilos }\end{array}$ & $\begin{array}{c}\text { Total } \\
\text { florines }\end{array}$ & Promedio \\
\hline 1. SANTA MARIA . . . . . & 67 & 244.5 & $3 \%$ & 28 & $272 ' 5$ & 4 \\
\hline 2. SAN JULIÁN $\ldots \ldots \ldots$ & 45 & 133 & $2^{\prime} 9$ & 14 & 147 & $3 \cdot 26$ \\
\hline 3. LA MAgdalena $\ldots \ldots$ & 80 & 242 & 3 & 31 & 273 & 34 \\
\hline 4. SAN PEDRO $\ldots \ldots \ldots$ & 20 & 60 & 3 & 7 & 67 & 3.35 \\
\hline S. SAN Miguel $\ldots \ldots \ldots$ & 11 & 29 & 26 & - & 29 & $2 \% 6$ \\
\hline 6. SANTA MARÍA & & & & & & \\
\hline DE LAS DUEÑAS & 6 & 16 & $2 \%$ & 1 & 17 & $2^{\prime} 8$ \\
\hline 7. SAN SALVADOR & 73 & 262 & $3 \%$ & 29 & 291 & 3'98 \\
\hline 8. SAN Nicolas & 33 & 109 & $3 \cdot 3$ & 14 & 123 & $3 \cdot 7$ \\
\hline 9. SAN JORGE . . & 35 & 236 & 67 & 33 & 269 & $7 \% 68$ \\
\hline 10. SAN JAIME . . & 68 & $244 ' 5$ & 3.6 & 19 & 263.5 & 3.87 \\
\hline TOTAL & 438 & 1.576 & 3.6 & 176 & 1.752 & 4 \\
\hline
\end{tabular}

La primera columna (Fuegos normales) expresa el número de vecinos nominalmente consignados en el censo.

En la segunda columna (Florines) se indica la cantidad que pagaron en conjunto los fuegos de la primera columna. El promedio resultante de flor. por fuego se indica en la tercera columna.

En la cuarta columna aparecen los florines pagados en conjunto por los que el texto califica de pegujaleros y pupilos, es decir, los vecinos aparentemente de menores posibilidades económicas. Conviene insistir en que el manuscrito no indica nunca el número de estos pegujaleros y pupilos, sino tan sólo la cantidad de florines que aportan globalmente en cada parroquia. Aunque cabría suponerles una aportación per capita inferior a 1 florín -que es la cuota mínima prevista por la ordenanza real- hay que señalar que en la nómina de «fuegos normales» de la parroquia de Santa María constan dos vecinos que contribuyen con medio florín cada uno (núm. 9 y 45 ).

la generalidad de los pueblos de la Ribera -por lo que he podido comprobar en una encuesta incompleta- se ajusta a la media de 2's florines. 
La quinta columna (total florines) es la suma de florines de las columnas segunda y cuarta.

El promedio de la sexta columna resulta de dividir la cifra de la quinta columna (Total florines) por la de la primera (Fuegos normales). Esta operación la hace el texto expresamente tan sólo para el total de las parroquias, que arroja con absoluta exactitud los 4 florines por fuego. Como desconocemos el número de "pegujaleros y pupilos», no podemos establecer el promedio real -no el ficticio de 4 flor.- probablemente poco superior a 2'5.

\section{Sospechas sobre presuntas manipulaciones de cifras}

Estas cantidades de florines reflejan exactamente los datos aportados por la nómina de vecinos cristianos. Ahora bien, ffueron los entregados de hecho al fisco regio? Parece claro que no, pues se detectan notables discrepancias con las cifras de otras partidas. En primer lugar los funcionarios de la Hacienda aceptaron como válida la cifra de 465 fuegos de cristianos (francos) considerados "podientes", que, a 2' 5 flor. por fuego, pagarían 1.162' 5 flor. Pero de esta cantidad descontaron por lo pronto los $37^{\prime} 5$ flor. correspondientes a los 15 vecinos que lograron pasar como «hidalgos», lo cual dejaba el total en 1.125'5 flor. A ellos habría que restar los correspondientes a los francos «no podientes», que se declara eran 125. Estos últimos no debían pagar, a juzgar por una letra del seynor rey -que adujo el recaudador-que de los non podientes non costreinniese et sobresobiese. Pero los oidores de Comptos no quedaron convencidos, y en nota marginal de la cuenta del recaudador anotaron severamente: No declaró quoáles eran los non podientes; es cargado aqui ata que aya letra de gracia ${ }^{61}$ bu. De modo que en definitiva no sabemos si se liquidaron los 317 florines que debían pagar (a 2' 5 flor. por fuego) los 125 «no podientes». Si se liquidaron, la suma total aportada por los "francos» de Tudela serían 1.432 florines.

Ninguna de estas cifras coincide, como vemos, con las del Cuadro VI, que dan la impresión de haber sido «maquilladas» para lograr a toda costa el promedio de $4 \mathrm{fl}$., promedio que no sabemos por qué razón se fijaron como meta.

En todo caso, los jurados de Tudela parecen tan expertos manipuladores de cifras y hábiles maniobreros ante el Fisco como sus colegas de Pamplona. En concreto, el apartado de «Pegujaleros y pupilos», cuyos componentes no se nombran ni numeran, pudo servir a los tudelanos de cómodo subterfugio para

61 bis. J. CARRASCO, La población, p. 413, tercer párrafo; p. 414, segundo y tercer párrafos y nota 25; p. 422, nota 87. 
defraudar a la Hacienda. La magnitud de esas presumibles ocultaciones se nos escapa, como parece que escapó a los recaudadores, impotentes ante las maniobras de los contribuyentes o, por mejor decir, de las autoridades concejiles, que son los auténticos responsables de estas artimañas.

También es verdad que, en último término, el Fisco se daba por satisfecho con obtener la recaudación de los $40.000 \mathrm{fl}$. en el cómputo final del reino. Asegurado ese objetivo, le eran más bien indiferentes los medios empleados a niveles inferiores, en un proceso recaudatorio "al por menor" que abandonaba a la responsabilidad de las autoridades locales, cerrando los ojos ante unos fraudes que se daban por descontados e inevitables. Pero el objetivo final no se perdía nunca de vista. Por eso los oidores de Comptos anotaron al margen de unas partidas de «no podientes» de ciertas localidades de la Ribera, de las que el recaudador pretendía se le descargara: Nota que estas partidas de los qui son dados por non podientes et non podientes se toman a present aqui en descarga ata tanto que sea visto si con estos non podientes complirán los $40.000 \mathrm{fl}$. Et si non complirán, serán escargados et cobrados. Los podientes et non podientes uno con otro deben responder en 2 florines et meyo segunt la comisión. (J. CARRASCO, La población, p. 422, nota 87 ).

\section{La contribución por parroquias}

Pero como vamos a detallar a continuación, lo más sorprendente en el caso de Tudela es que no se atuvieron a las cuotas de 1-2-3-4 fl. previstas en la circular del rey, sino que superaron muy ampliamente este abanico sobre todo hacia arriba, aplicando cuotas desde 0' 5 hasta los 14 florines.

Véase el detalle de cada una de las parroquias:

\section{Santa María ${ }^{62}$}

\begin{tabular}{lll} 
Florines & Fuegos & $\begin{array}{c}\text { Total } \\
\text { Florines }\end{array}$ \\
\hline 14 & 1 & 14 \\
11 & 4 & 44
\end{tabular}

${ }^{62}$ En la edición de (J. CARrasco, falta el teórico n. ${ }^{\circ} 41$ de esta parroquia: «Fernando de Sant Antón, II flor. et medio». Léase como "María Périz del Forno» la n. 2 ("María Périz de Sorion en la edic.); como Trobat, el n. 6 (Nobat en la edic.); como Serán, los núms. 8, 22 y 37 («Serra», «Sen», en la edic.); como «Pero Xemeniz de Verde», el n. ${ }^{\circ} 13$ («Unde»); como 


\begin{tabular}{lcc} 
Florines & Fuegos & $\begin{array}{c}\text { Total } \\
\text { Florines }\end{array}$ \\
\hline 10 & 1 & 10 \\
9 & 1 & 9 \\
8 & 2 & 16 \\
7 & 1 & 7 \\
6 & 3 & 18 \\
5 & 4 & 20 \\
$4 ' 5$ & 2 & 9 \\
4 & 8 & 32 \\
3 '5 & 1 & $3{ }^{\prime} 5$ \\
3 & 4 & 12 \\
'.5 & 4 & 10 \\
2 & 9 & 18 \\
1'5 & 2 & 3 \\
1 & 18 & 18 \\
'.5 & 2 & 1 \\
\hline Total & 67 & $244^{\prime} 5$
\end{tabular}

Falta en la edición la mención de los $28 \mathrm{fl}$. de los pegujaleros (que ayudaron a los dichos fuegos a complimiento de IIII fl. por fuego, XXVIII $f l$., como se lee claramente en el ms.) que, sumados a los $244^{\prime} 5 \mathrm{fl}$. de los contribuyentes normales, arroja el total de 272 ' $5 \mathrm{fl}$. de esta parroquia.

Más adelante, en una recapitulación final, citaré a los principales contribuyentes, con las noticias históricas que sobre cada uno poseemos.

\section{San Julián ${ }^{63}$}

\begin{tabular}{ccc} 
Florines & Fuegos & $\begin{array}{c}\text { Total } \\
\text { Florines }\end{array}$ \\
\hline 9 & 3 & 27
\end{tabular}

"Rodrigo de los Fayos», el n.॰ 23 ( «Suyos»); «Sancho Milán» el n.॰ 24 ( Sancho Rulán»); "Sevilia» el n. 53 («Senilia»); «Johan l'escrivano» el n.0 61 ("Johan Sesmano»); «Estevan de Cuevas» el n. 65 («Estevan de Menos»). El n. 15 leo "Johan de Coscolina, VI flor.» ("Johan de Costalina, VII flor." en la edic.).

El n. ${ }^{\circ}$ 42, Rodrigo de Sant Adrián, fue considerado hidalgo ( J. CARRASCO, La población, p. $413, n .^{\circ} 1$ ).

${ }^{63} \mathrm{El} \mathrm{n} .{ }^{\circ} 4$ creo debe leerse «Domingo Cahuerga». Tener en cuenta que lograron pasar 


\begin{tabular}{lcc} 
Florines & Fuegos & $\begin{array}{c}\text { Total } \\
\text { Florines }\end{array}$ \\
\hline 8 & 1 & 8 \\
6 & 1 & 6 \\
5 & 3 & 15 \\
4 & 4 & 16 \\
3 & 5 & 15 \\
2.5 & 6 & 15 \\
2 & 8 & 16 \\
1.5 & 2 & 3 \\
1 & 12 & 12 \\
\hline Total & 45 & 133
\end{tabular}

Esta parroquia de San Julián abarcaba el espacio urbano que en época musulmana había ocupado la antigua Judería, limitando con el curso del río Queiles y la muralla.

\section{La Magdalena ${ }^{6+}$}

\begin{tabular}{ccc} 
Florines & Fuegos & $\begin{array}{c}\text { Toral } \\
\text { Florines }\end{array}$ \\
\hline 10 & 1 & 10
\end{tabular}

como hidalgos, con cuota rebajada, Pedro López de Olleta (.$\left.^{\circ} 3\right)$, Iñigo de Larrángoz (n. $\left.{ }^{\circ} 7\right)$, Jimero de Eriete (n. 8), Gracia de Sessa (n. $\left.{ }^{\circ} 44\right)$ y, tal vez, Semén Crupán (¿Conpán?) (J. Carrasco, La población, p. 413, n. 3, 4, 5, 6 (?); y p. 424, n. 11 (?), 12, 17 y 19).

Estimo debe leerse como Gonzalvo de Sentía el n. ${ }^{\circ} 11$, como Gil de Arasciel el n. 13 , como Pero Sánchiz Jacobín el n. ${ }^{\circ}$ 14, como Semeno de Luessia el 15, y como García Ferrándiz de Villasandrán el 16.

La cuota del n. 18 ( Estevanía la de don Bernart, con su yerno») no parece ser $3 \mathrm{fl}$., sino 2, o tal vez 1 . En cambio, la del n. 24 ( $P$ Pero Sánchiz l'Agoado») son $4 \mathrm{fl}$., n. ${ }^{\circ} 3$. Es preferible leer el n. 37 como "Martín don Costal».

${ }^{64}$ Tras el teórico n. ${ }^{\circ} 30$ ("Vicent de Roncal»), el editor ha omitido el n. 31 ( Bertholomeo Catalán, $5 \mathrm{fl.»).} \mathrm{El} \mathrm{n.}{ }^{\circ}$ 2, Arnalt de Cabañillas, cotiza $4 \mathrm{fl} ., \mathrm{n} .{ }^{\circ} 3$. El n. 23 debe leerse "Martín (no "María») de Lodosa», y como "Matheo de Tarascona" el 24. Es dudoso el nombre de los n. 27 y 34, que podrían leerse Flotas, en lugar de Flores.

El núm. 28, Martín Conparat, tiene de cuota 1,5 fl., no 2,5. Juzgo preferible leer el 43 como «Pascoal Terrén»; como Maria (no "Martín») Périz de Sanguessa, el n. ${ }^{\circ} 53$; y como García Martíniz de las Massaderas, el n. ${ }^{\circ} 63$. La cuota del $n .{ }^{\circ} 75$ son $9 \mathrm{fl}$. (en lugar de 4); y 1,5 fl. la del n. ${ }^{\circ} 79$ (Sancho de Acugia), en lugar de 1 florín. 


\begin{tabular}{lcc} 
Florines & Fuegos & $\begin{array}{c}\text { Tocal } \\
\text { Florines }\end{array}$ \\
\hline 9 & 1 & 9 \\
8 & 4 & 32 \\
6 & 1 & 6 \\
5 & 7 & 35 \\
4 & 14 & 56 \\
3.5 & 1 & 3.5 \\
3 & 7 & 21 \\
2.5 & 3 & 7.5 \\
2 & 15 & 30 \\
1.5 & 4 & 6 \\
1 & 22 & 22 \\
\hline Total & 80 & 238
\end{tabular}

No cuadran exactamente las cifras de esta parroquia. El texto dice que los pegujaleros pagaron 31 florines, y que el total de la parroquia -contando esos $31 \mathrm{fl}$.- fue de $273 \mathrm{fl}$. Según eso, deberían ser 242 los correspondientes a los fuegos normales, no los 238 que arroja mi cuadro. Desconozco a qué error contable o gráfico del ms. es achacable este desfase de 4 florines.

\section{San Pedro}

\begin{tabular}{llc} 
Florines & Fuegos & $\begin{array}{c}\text { Total } \\
\text { Florines }\end{array}$ \\
\hline 9 & 1 & 9 \\
8 & 2 & 16 \\
4 & 3 & 12 \\
3 & 3 & 9 \\
2 & 4 & 8 \\
1 & 6 & 6 \\
0.5 & 1 & 0.5 \\
\hline Total & 20 & 60.5
\end{tabular}




\section{San Miguel ${ }^{6 s}$}

\begin{tabular}{llc} 
Florines & Fuegos & $\begin{array}{c}\text { Total } \\
\text { Florines }\end{array}$ \\
\hline 5 & 1 & 5 \\
4 & 3 & 12 \\
3 & 1 & 3 \\
2 & 3 & 6 \\
1 & 3 & 3 \\
\hline Total & 11 & 29
\end{tabular}

En esta parroquia de tan pocos vecinos -situada al pie meridional del cerro del castillo- no hay pegujaleros ni pupilos, por lo que el promedio es claramente de $2^{\prime} 6 \mathrm{fl}$.

\section{Santa Maria de las Dueñas}

\begin{tabular}{ccc} 
Florines & Fuegos & $\begin{array}{c}\text { Total } \\
\text { Florines }\end{array}$ \\
\hline 6 & 1 & 6 \\
3 & 2 & 6 \\
2 & 1 & 2 \\
1 & 2 & 2 \\
\hline Total & 6 & 16
\end{tabular}

El texto dice que hay un pegujalero pastor, que abona 1 florín, lo cual hace el total de 17 florines.

$$
\text { 7. San Salvador }{ }^{66}
$$

\begin{tabular}{lll} 
Florines & Fuegos & $\begin{array}{c}\text { Total } \\
\text { Florines }\end{array}$ \\
\hline 14 & 1 & 14 \\
12 & 2 & 24
\end{tabular}

"Séase como «Sancho de Calchetas» el último vecino.

${ }^{66}$ La cuota del n. ${ }^{\circ} 1$ son tres fl., no cuatro. Léase como "García d'Aynsa» el n. ${ }^{\circ} 12$. La 


\begin{tabular}{lcc} 
Florines & Fuegos & $\begin{array}{c}\text { Total } \\
\text { Florines }\end{array}$ \\
\hline 10 & 3 & 30 \\
7 & 3 & 21 \\
6 & 5 & 30 \\
5 & 5 & 25 \\
4 & 8 & 32 \\
3.5 & 1 & 3.5 \\
3 & 7 & 21 \\
2.5 & 2 & 5 \\
2 & 20 & 40 \\
$1 ' 5$ & 1 & $1 ' 5$ \\
1 & 15 & 15 \\
\hline Total & 73 & 262
\end{tabular}

Adviértase que Martín Ferrándiz de Cáseda (núm. 59) no desembolsó en realidad los 5 florines que se le asignaron en esta relación, sino sólo 2 en calidad de hidalgo ".

\section{San Nicolás}

\begin{tabular}{ccc} 
Florines & Fuegos & $\begin{array}{c}\text { Total } \\
\text { Florines }\end{array}$ \\
\hline 14 & 1 & 14 \\
10 & 3 & 30 \\
5 & 1 & 5 \\
4 & 3 & 12 \\
$3^{\prime} 5$ & 1 & $3^{\prime} 5$ \\
3 & 4 & 12 \\
$2^{\prime} 5$ & 1 & $2 ' 5$ \\
2 & 11 & 22
\end{tabular}

cuota del n. 20 (la mujer de Pedro el Santo) es de 1 florín, no dos. Léase el n. 24 como «Elvira de la Flota». Me inclino por leer el núm. 27 como «Pedro de las Eras» (el mismo patronímico que el $n .{ }^{\circ} 29$, el cual paga $10 \mathrm{fl}$., no cinco). Léase el $n .{ }^{\circ} 31$ como "Gil de los Fayos». La cuota del n. 39 (Johan Picador) quede claro que son $4 \mathrm{fl}$. El n. 43 es «Furtuyno». La cuota del n." 46 (Xemen Just) son 6 fl., en lugar de 3. El n. ${ }^{\circ} 54$ podría leerse Sancha Gruta o Gonta. Léase como Micolau el "Nicolau» del último vecino.

${ }^{67} \mathrm{~J}$. CARrasco, La población, p. 413, n. ${ }^{\circ}$; p. 424, n. ${ }^{\circ} 13$. 


\begin{tabular}{ccc} 
Florines & Fuegos & $\begin{array}{c}\text { Total } \\
\text { Florines }\end{array}$ \\
\hline 1 '5 & 1 & 1.5 \\
1 & 7 & 7 \\
\hline Total & 33 & $109 ' 5$
\end{tabular}

Hay que señalar que Rodrigo de Cascante (núm. 13) no abonó los 2 ' $5 \mathrm{fl}$. que aquí se le asignaron sino, al parecer, $3 \mathrm{fl}$. como hidalgo ${ }^{68}$. De acuerdo con mis cálculos sobraría el pequeño pico de medio florín, pues según el ms. los pegujaleros contribuyeron con $14 \mathrm{fl}$. al total de $123 \mathrm{fl}$.

$$
\text { 9. San Jorge }{ }^{69}
$$

\begin{tabular}{ccc} 
Florines & Fuegos & $\begin{array}{c}\text { Total } \\
\text { Florines }\end{array}$ \\
\hline 14 & 4 & 56 \\
13 & 1 & 13 \\
12 & 2 & 24 \\
11 & 1 & 11 \\
10 & 4 & 40 \\
8 & 1 & 8 \\
7 & 5 & 35 \\
5 & 1 & 5 \\
4 & 7 & 28 \\
3 & 2 & 6 \\
2 & 3 & 6 \\
1 & 4 & 4 \\
\hline Total & 35 & 236
\end{tabular}

Hay que advertir que los pegujaleros y pupilos contribuyeron con $33 \mathrm{fl}$., no con 32 como consta en la edición.

Como puede observarse, esta parroquia arroja el promedio más alto de florines per cápita. Ciertamente en ella se avecindaban algunas de las familias

${ }^{68}$ Id., id., p. 413, n. 2 .

${ }^{69}$ Juzgo preferible leer como Rodrigo de Grez el $n .{ }^{\circ} 12$ («Rodrigo de Oroz»), y como Sancho d'Ansón el n.॰ 20 ( «Sancho d'Ausón»). Léase Xemen (no "Xemeno») el n. 26. La cuota del n. 32 (la mujer de Johan Martiniz Lastero) es de tres fl., no de cuatro. 
más acaudaladas de la burguesía, cuya aportación fue en muchos casos acorde con sus posibilidades económicas, según detallaremos más adelante.

Señalemos que Fernando de Araciel (núm. 14) no pagó los 10 fl., ni Juan de Eslava (núm. 31) los 12 fl. asignados, sino sólo 2 y 3, respectivamente, pues lograron pasar como hidalgos"

\section{San Jaime "}

\begin{tabular}{ccc} 
Florines & Fuegos & $\begin{array}{c}\text { Total } \\
\text { Florines }\end{array}$ \\
\hline 14 & 2 & 28 \\
13 & 1 & 13 \\
8 & 2 & 16 \\
7 & 1 & 7 \\
6 & 10 & 60 \\
5 & 2 & 10 \\
4 & 11 & 44 \\
3 & 6 & 18 \\
2 '5 & 1 & 2 '5 \\
2 & 14 & 28 \\
1 & 18 & 18 \\
\hline Total & 68 & $244^{\prime} 5$
\end{tabular}

Hay que advertir que Juana de Landa (núm. 23) en realidad no abonó los 7 florines asignados aquí, pues pasó por hidalga. Pedro Caritat (núm. 34), que también logró ser considerado hidalgo, pagó sólo $4 \mathrm{fl}$. en lugar de los 14 que aquí se le adjudicaron "2. Por la misma razón, cabe sospechar que tampoco Pedro de Ainsa (núm. 1) satisfizo la cuota de $14 \mathrm{fl}$. con que figura en esta lista ${ }^{73}$.

"J J. Carrasco, La población, p. 413, n.* 10 y 11; p. 424, n.* 9 y 14.

$"$ Creo preferible leer como "Romeo d'Ozcoz" el n. 4 (Romeo d'Ezcoz); como Aparicio del Maestro el $n .{ }^{\circ} 11$ (Aparitio del maestro), como «Domenga la Marina» el n. ${ }^{\circ} 20$, y como Johan Ruiz de Lagunieilla el n.0 22 ("Laguincilla»). Léase como "Micolau» el «Nicolau" n. 27 ; como "Millia» el "Millian» (núm. 47) y como García Labadán el siguiente ( LLadaban»). Súplase la «e» en el n. 63 (Pedro el Crespo). Juzgo preferible transcribir «de la Buendía» el n. ${ }^{\circ} 64$.

Son siete -no ocho- los flor. asignados a Juana de Landa (núm. 23), y cuatro -no treslos de Miguel de Soria (n.0 33)

72 J. Carrasco, La población, p. 413 , n.* 12 y 14; p. 424, n. 4 .

${ }^{73}$ En realidad no desembolsó cantidad alguna, si lo identificamos con el «Pero Xemeniz d'Ainsa” de J. Carrasco, La población, p. 413, n. ${ }^{\circ} 13$. 


\section{La contribución de las familias destacadas}

De modo semejante a como hemos hecho con Pamplona, y con objeto de resaltar el llamativo contraste entre ambas ciudades, vamos a examinar a continuación la cuantía con que contribuyeron a la ayuda los apellidos conocidos de Tudela. Helos aquí, ordenados según los florines que se les asignaron.

\section{4 florines}

1. Pedro Iñiguez de Ujué, el Mayor (Santa María, núm. 49). Fue alcalde de Tudela en 1350, cargo que probablemente desempeñaba en 1366 un pariente, tal vez hijo suyo, Sancho Iñiguez de Ujué ${ }^{14}$. De este linaje de mercaderes y cambistas alguno siguió la carrera eclesiástica, como Pascual Iñiguez de Ujué, maestrescuela del cabildo de Tudela en 1350 ". Este Pedro Iñiguez de Ujué pretendía pasar por hidalgo, pagando sólo 4 florines, y parece que lo consiguió ${ }^{76}$.

2. Elvira de la Flota (San Salvador, núm. 24). Miembro de otra familia relevante de la burguesía, a la que pertenece asimismo un Bartolomé de la Flota que contribuyó con $7 \mathrm{fl}$. (vide postea). A fines del siglo, la viuda de Juan de la Flota, residente en la parroquia de la Magdalena, había efectuado préstamos a particulares por valor de 175 libras ".

3. Juan Pastor (San Nicolás, núm. 15). No todos los Pastor parecen adinerados, pues hay un Pedro Pastor en la parroquia de San Julián (núm. 35)

${ }^{74}$ J. Carrasco, La población, pp. 89 y 379. Sancho Iñiguez de Ujué fue conceptuado como hidalgo en 1366, y cotizó a la ayuda con 4 flor. (id., p. 424, n. ${ }^{\circ} 1$ ). Aparece como alcalde en 1363 y 1369 (J. ZABALO, Participación navarra en la guerra de los dos Pedros. La expedición de Murviedro», Homenaje a J. M." Lacarra», "Príncipe de Viana», Anejo 3 (1986), p. 778 , nota 4 .

15 B. LEROY, Recherches sur les juifs de Navarre à la fin du Moyen Age, REJ, jul-dic. 1981, p. 392: de la misma, Cartul. del infante Luis, doc. 119.

${ }^{76}$ B. LEROY, Tudela, une ville de la vallée de l'Ebre aux XIII-XIV siècles, "Actes du XI Congrès des Historiens médiévistes de l'enseignement superieur», Lyon, 1981, p. 204, nota 30. J. Carrasco, Propietarios judios en la Ribera tudelana de Navarra después de la Peste Negra (1348-86), en "Concejos y Ciudades en la Edad Media Hispánica», Fundación Sánchez Albornoz, 1990, p. 72, n. 18 ; del mismo, La población, p. 424, n. ${ }^{\circ} 3$, en donde se le asignan 4 flor. como hidalgo. María Iñíguez de Ujué, hermana de Iñigo y viuda del caballero Ferrán Ruiz de Caravantes, hizo testamento en 1383 (B. LEROY, Les villes dans le monde ibérique, CNRS, Paris 1982, p. 45 ss., publica el testamento).

$"$ J. Carrasco, Propietarios judios (citada en la nota anterior), p. 72, n. 5. 
que contribuye únicamente con 2'5 f. Este Juan Pastor casó con Catalina Garceiz del Bayo, y al morir dejó como tutor de sus hijos a Juan Caritat de Milagro. "

4. Lope Martínez de las Navarras (San Jorge, núm. 1). Desempeñará el cargo de justicia de Tudela en 1370-73. Desconozco el parentesco que le unía a Ferrant Lópiz de las Navarras, vecino de la parroquia de Santa María, que había realizado préstamos por valor de 108 libras a fines de siglo. Estaba emparentado con los Ujué y vivía todavía en $1383^{\prime \prime}$.

5. Juan Renalt (San Jorge, núm. 3). Era justicia de Tudela en estos años 1360-69, aunque no lo indica el censo expresamente, si bien alude a su condición de caballero. Llegó a ser alcalde de Tudela en 1379-90. En 1363 había tenido que prestar $30 \mathrm{fl}$. a Carlos II para financiar la expedición militar que capitaneó el infante Luis hasta Murviedro, en apoyo de la campaña de Pedro el Cruel contra Aragón. También aparece realizando más tarde préstamos a particulares por valor de 357 libras ${ }^{\text {*o }}$.

6. Inés Caritat y su bijo Jimeno (San Jorge, núm. 24). De familia burguesa bien conocida, esta Inés es la única que cotiza de acuerdo con la presumible capacidad económica del linaje, pues su pariente Pedro Caritat, vecino de San Jaime (núm. 34), que había sido baile y justicia de Tudela, logró pasar como hidalgo y abonó sólo $4 \mathrm{fl}$., en lugar de los 14 que se le habían asignado en principio ${ }^{\text {s1 }}$.

7. Gutier Garcia (de Aguilar) (San Jorge, núm. 21). Años más tarde

7 B. LEROY, Tudela en 1381-83 à travers le registre du notaire Martin don Costal, «Príncipe de Viana», 179 (1986), nota 51, y J. BalezTena, Catálogo de Comptos. Papeles sueltos, doc. 108. Repárese que hay un García del Bayo que paga 9 florines en esta ayuda de 1366.

79 J. Carrasco, Propietarios judios, p. 72, n. ${ }^{\circ}$ 15. Junto con Sancho Iñiguez de Ujué, este Lope Martínez de las Navarras había sido en 1356-57 comisario para recaudar en Tudela la ayuda de $10 \mathrm{~s}$. por fuego (CASTRO, Cat. Comptos, 2, núm. 1055). Ya en 1290-91 un Martínez de las Navarras aparece como justicia de Tudela.

80 B. LEROY, Vie et mort à Tudela en 1380-83. Le testament de Bernarda del Pimbo, "Mélanges J. Gautier Dalché», Nice, 1983, p. 145; de la misma, Les villes dans le monde ibérique, citada en la nota 76, p. 48; J. ZABALO, Participación navarra en la guerra de los dos Pedros. La expedición de Murviedro (citada en nota 74), p. 778, nota 4; J. CARRASCO, Propietarios judios, p. 72. En 1357-60, J. Renalt, junto con Pedro Caritat, era arrendatario del almudi de Tudela por cien libras blancas anuales (J. ZABALO, La administración, p. 357358). Adviértase que hay otro Arnalt Renalt en esta misma parroquia (n. ${ }^{\circ} 33$ ), tasado en 8 florines.

${ }^{81}$ Este Pedro Caritat realizó préstamos por valor de 136 libras (J. CarRasco, Propietarios judios, p. 72). Casado con María de Esparza, murió en 1383. Fue suegro de Martín Jiménez de Ainsa, que a su vez era hijo de una Renalt de Ujué (B. LEROY, Vie et mort à Tudela -citada en nota 80- p. 145, nota 11). 
aparece como el máximo prestamista a particulares, con la importante suma total de 842 libras ${ }^{32}$.

8. Pedro de Ainsa (San Jaime, $n .^{\circ} 1$ ). Si lo identificamos con el Pedro Jiménez de Ainsa que logró pasar por hidalgo, resulta que sólo contribuyó con 4 f. " Pedro Jiménez de Ainsa había prestado 70 libras a Carlos II para la campaña de Normandía de 1355, y en 1383 sabemos que poseía una casa en la parroquia de San Jorge ${ }^{84}$. Ya hemos aludido a los lazos de parentesco que unían a este linaje con los Arnalt de Ujué y los Caritat (nota 81).

\section{3 florines}

1. García de Beraiz (San Jorge, núm. 27). Sabemos que casó con Domenga de Ribaforada y que fue suegro de Miguel de Guerguetiain, que a su vez contribuyó con $4 \mathrm{fl}$. (Santa María, núm. 20) ". Nótese que a Gil de Beraiz (San Nicolás, núm. 28) se le asignó una cuota de sólo 4 florines.

2. Martín Gonzálviz (San Jaime, núm. 41). Me atrevo a identificarlo con el Martín Gonzálviz de Morentin que casó con Bernarda del Pimbo, tía del canónigo tudelano Ponz de Eslava. Según eso, en realidad fue considerado hidalgo y sólo desembolsó 4 florines ${ }^{*}$.

\section{2 florines}

1. Pascual Jiménez de Verde (San Salvador, núm. 68). Podemos observar que un pariente, Bartolomé de Verde, fue tasado en $10 \mathrm{fl}$., mientras que tanto Martín de Verde como Pedro Jiménez de Verde fueron tasados únicamente en 4 florines ${ }^{87}$.

${ }_{82}$ J. Carrasco, Propietarios judios, p. 72. J. Baleztena, Catálogo de Comptos. Papeles sueltos, n. 99; B. LEROY, Les villes dans le monde ibérique, p. 50.

3. J. Carrasco, La población, p. 413, n. 13. en p. 149.

${ }^{84}$ J. CASTRO, Catálogo de Comptos, II, doc. 708. B. LeROY, Vie et mort à Tudela, doc.

8s B. LEROY, Les villes du monde ibérique, p. 50; de la misma, Tudela en 1381-83 à travers le registre du notaire Martin don Costal, ya citado, p. 735. La grafía moderna de este apellido es Beraiz. Por su parte, Miguel de Guerguetiáin era un destacado mercader (ver Peajes de Tudela de 1365 y 1366).

"6. BeROY, Vie et mort à Tudela, p. 144. El testamento de Bernarda de Pimbo data de setiembre de 1383. Sobre la condición de hidalgo de Martín Gonzálviz, J. CarrasCo, La población, p. 424, n. 2.

" J. Baleztena, Cat. Papeles sueltos, n.o 22. 
2. Juan de Eslava (San Jorge, núm. 31). Aunque se le señaló en principio una cuota de 12 fl., en realidad consiguió pagar sólo 3, pasando como hidalgo ".

3. Juan de San Martín (San Jorge, núm. 30). Había sido baile de Tudela en 1361-62, y será justicia en 1375-78.

\section{1 florines}

1. Fortún de Salinas (Santa María, núm. 4). Adviértase que un Ibáñez de Salinas contribuyó con diez florines.

2. Sancho Ros (Santa María, núm. 29). Otros Ros cotizaron sólo 5 y 4 florines, respectivamente.

3. Pascual de Pola (Santa María, núm. 30). Junto con Miguel García de los Arcos, este Pascual de Pola administró el peaje mayor de Tudela el año 1358 (J. ZABALO, La administración de Navarra en el siglo XIV, p. 357). Un Pascual Pola está documentado en el registro del peaje de Tudela de 1365.

4. Pedro Jurdán (Santa María, núm. 60). Sabemos que llegó a realizar préstamos a particulares por la suma total de 140 libras ${ }^{89}$. Recordemos que otros Jurdán son conocidos mercaderes del burgo de San Saturnino de Pamplona, como hemos destacado en páginas anteriores.

5. Jimeno Barrena (San Jorge, núm. 26).

\section{0 florines}

1. El alcalde, que parece ser Sancho Iñiguez de Ujué (nota 74), vecino de la parroquia de Santa María (núm. 36).

2. Miguel Renalt y su bermano (San Nicolás, núm. 8). Cabe suponerlos parientes del Renalt de Ujué, justicia de Tudela, que cotizó 14 florines. Otro Renalt contribuyó con 8 florines.

3. Bartolomé de Verde (San Salvador, núm. 28). Ya hemos citado otro pariente que contribuye con $12 \mathrm{fl}$. en esta misma parroquia, y hay otros Verde tasados en 4 florines.

4. Lope Ibáñez de Salinas (San Jorge, núm. 4). En su calidad de burgués

${ }_{88}$ J. Carrasco, La población, p. 413, n. ${ }^{\circ} 11 ;$ p. 424, n. ${ }^{\circ}$. Un Ponz de Eslava fue canónigo de Tudela y recibidor de la merindad de Ribera en 1368-74 (J. ZABALO, La administración, p. 152), cuyo parentesco con Martín Gonzálviz de Morentin hemos indicado en el texto correspondiente a la nota 86.

89 J. CARrasco, Propietarios judíos, p. 72. 
acaudalado había tenido que contribuir con 40 florines al préstamo forzoso que impuso Carlos II en 1363 para financiar la expedición a Murviedro ${ }^{90}$.

5. Pedro Iñiguez de Ujué, el Joven (San Jorge, núm. 6). Ya hemos aportado noticias sobre esta destacada estirpe burguesa al citar al homónimo que contribuyó con 14 florines (notas 74 y ss.).

6. Iñigo Pérez de Ujué (San Nicolás, núm. 2). Aunque probablemente emparentado con el anterior, carezco de noticias concretas sobre él.

7. Juan de Flotas (La Magdalena, núm. 34). En calidad de miembro destacado del estamento mercantil tudelano, en 1363 había tenido que contribuir con 30 florines al préstamo forzoso impuesto por el monarca para la campaña de Murviedro ". Hemos citado otro de la Flota con cuota de $14 \mathrm{fl}$. y aparece otro en el grupo de 7 florines.

8. Juan Iñiguez (San Salvador, núm. 3). Carezco de noticias sobre este vecino, que hay que suponer adinerado.

9. Juan de las Heras (San Salvador, núm. 29). Lo hemos visto contribuir con 15 florines -junto con su hermano Pedro, que cotizó 6 fl. en esta ayuda de 1366- al préstamo forzoso del año 1363.

10. Estebania Cortel (San Nicolás, núm. 1). Llegó a efectuar préstamos a particulares por un montante global de 163 libras ${ }^{22}$.

11. Fernando de Araciel (San Jorge, núm. 14). Aunque tasado en 10 florines, en realidad sólo pagó 2 , pasando como hidalgo.

91 Ya hemos visto que las aportaciones más cuantiosas a ese empréstito fueron las del alcalde de Tudela, Sancho Iñiguez de Ujué ( 150 florines), y Pedro Jiménez de Ainsa ( $100 \mathrm{fl}$.). En orden decreciente, contribuyeron también el judío Cohen ( $34 \mathrm{fl}$.), el justicia Juan Renalt (30 fl.), Pedro Caritat y Juan de Flotas (30 fl. cada uno), Guillén de Agreda (20 fl.), los cambistas don Ferrando y Fernando Pérez de Araciel - $15 \mathrm{fl}$. cada uno- y, con esa misma cifra, Pascual Falcón, García Catalán, Aparicio del Maestro y los hermanos Juan y Pedro de las Heras, todos vecinos de Tudela (J. ZABALO, Participación navarra en la guerra de los dos Pedros, "Homenaje a Lacarra», nota 4).

Este Lope Ibáñez de Salinas reclamó en 1383 la enorme suma de 2.000 florines como indemnización al haber sido afrentado con el infamante insulto de gafo mesiello (leproso) (B. LEROY, Tudela en 1381-83, p. 738). Sabemos que mantenía relaciones económicas con Zaragoza [B. LEROY, Les relations de Tudela et Saragosse au XIV siècle, Homenaje a Lacarra, "Príncipe de Viana" (1986), p. 465, nota 7].

91 Ver nota anterior. Leído como «Juan de Flores» por el editor. Habrá que leer asimismo como Flotas el «Bertolomeo de Flores» $-n .^{\circ} 27$ de la misma parroquia de La Magdalena- tasado en $4 \mathrm{fl}$. para la ayuda.

92 J. CARrasco, Propietarios judios, p. 72, leída como Torcel. Junto con su hermana Elvira fundó una capellanía perpetua en S. Nicolás, donde querían ser enterradas según el testamento de agosto de 1381 (B. LEROY, Tudela, une ville de la vallée de l'Ebre, citada en nota 76 , p. 205 , nota 39 ).

${ }^{9} \mathrm{~J}$. CarrasCo, La población, p. 413, n. ${ }^{\circ} 10$; p. 424, n. ${ }^{\circ} 14$. 
12. Juan Jiménez don Bernart (San Jorge, núm. 22). Sabemos que realizó préstamos a particulares por valor de 146 libras ${ }^{24}$. Nótese que un Pedro

Jiménez don Bernart, vecino de San Salvador (núm. 66) contribuía sólamente con 3 florines a esta ayuda del año 1366.

\section{9 florines}

1. Guillén de Agreda (Santa María, núm. 51). Llegó a ser baile de Tudela a partir de 1373, y a continuación fue recibidor de la merindad de Ribera (1374-92) "'.

2. Pedro de Roncal, con sus hijos (San Pedro, núm. 10). Obsérvese que otro Roncal cotizó 8 florines.

3. Juan Serrano (San Julián, núm. 6). Carezco de noticias suplementarias sobre este tudelano.

4. García del Bayo (San Julián, núm. 36). De familia emparentada con los Pastor y relacionada con los Caritat, este García del Bayo realizó préstamos a particulares por importe de 119 libras ${ }^{*}$. Nótese que un Juan del Bayo contribuye a esta ayuda con $6 \mathrm{fl}$., y otro Pedro del Bayo, también vecino de San Salvador (núm. 34), tan sólo con 2 florines.

5. Bartolomé de Magallón (San Julián, núm. 39). Nos consta que llegó a realizar préstamos a particulares por valor de 95 libras ${ }^{97}$.

6. Nicolás de Cintruénigo (La Magdalena, núm. 75) ${ }^{98}$. Un Gonzalo García de Cintruénigo había sido justicia de Tudela en 1350-59.

\section{8 florines}

1. Vicente de Roncal (La Magdalena, núm. 30). Ya hemos citado a otro miembro de este linaje -Pedro de Roncal- que contribuyó con 9 florines.

2. Amalt Renalt (San Jorge, núm. 33). Hay que suponerlo perteneciente a la destacada familia de los Renalt de Ujué, uno de cuyos miembros -Juan Renalt, justicia de Tudela- contribuyó con $14 \mathrm{fl}$., mientras que Juana Renalt sólo pagó 1'5 fl. (San Julián, núm. 43) ${ }^{\text {}}$.

94 J. Carrasco, Propietarios judios, p. 72.

9s J. ZABAlo, La administración, p. 152. En 1366 compró un lote de tierras de propiedad real en el término de Soladrón (B. LEROY, Tudela, une ville, nota 24).

\% J. Carrasco, Propietarios judios, p. 72.

"Id., id.

${ }_{98}$ Ya hemos advertido en su momento que en la edición se le atribuyen erróneamente 4 florines de cuota.

99 En 1353 este Arnalt Renalt tomó en alquiler por tres años, a razón de cinco libras 
3. Miguel de Villanueva (Santa María, núm. 1), del que no poseo otros datos.

4. Bartolomea de Calchetas, con sus hijos (Santa María, núm. 62). A pesar de su viudez se deduce que era de buena posición económica.

5. Gracia de Sessa (San Julián, núm. 44). Nos queda la duda de si puede identificarse con la Gracia de Sesma -que sería la lectura correcta- que logró ser tasada sólo en 3 florines, en su condición de hidalga ${ }^{100}$.

6. Dominga de Larraga (La Magdalena, núm. 15). Es la tercera mujer tasada en 8 florines, como vemos, pero no consta si era viuda o soltera.

7. Sancho Tejero ("Teillero») (La Magdalena, núm. 18).

8. Sancho de Milagro (La Magdalena, núm. 73). Probablemente emparentado con los Caritat ${ }^{101}$.

9. Pedro Ferrándiz de Castejón ("Castellón») (San Pedro, núm. 8).

10. Garcia Catalán (San Pedro, núm. 12). Sin duda tenía suficientes recursos económicos, pues hubo de aportar $15 \mathrm{fl}$. al préstamo forzoso que exigió el rey para la campaña de Murviedro de tres años antes ${ }^{102}$.

11. Juan de Gris (San Jaime, núm. 6). Se le cita en 1391 como demandado en cierto pleito, junto con otros vecinos de Tudela ${ }^{103}$.

12. Pedro Bichio (San Jaime, núm. 15). Carezco de otras noticias sobre él.

anuales, una casa propiedad de la cofradía de Santiago. Se deduce que era comerciante, pues los cofrades le recomendaron que no almacenara allí grandes depósitos de aceite ni otros pesos, porque se podría hundir el pavimento (B. LEROY, Tudela, une ville, nota 42).

${ }_{100}$ Con la cifra de $3 \mathrm{f}$. tachada, se la cita como «madre de García Yñiguiz, fillo de maestre escolan (J. CARRASCO, La población, p. 413). No tengo datos para deducir que ese "maestre escola» sea el canónigo Ponz de Eslava, que ostentaba esa dignidad capitular en Tudela. Podría referirse a Pascual Iñiguez de Ujué, que lo fue con anterioridad (nota 75).

${ }^{101}$ Un Jimeno de Milagro y un Juan Caritat de Milagro, vecinos de Tudela, avalaron como testigos el testamento de María Iñiguez de Ujué en 1381 (B. LEROY, Les villes dans le monde ibérique, CNRS, Paris 1982, p. 48). Jimeno de Milagro representó a Tudela en la coronación de Carlos III en 1390, y fue recibidor de la Ribera (1395-1418) (J. ZABALO, La administración, p. 153 y J. GoÑI, La formación intelectual, "EEMCA", X, doc. 347).

En cuanto al Tejero citado en el n. ${ }^{\circ} 7$ de esta relación de los tasados en 8 fl., recordemos que un Pedro Tejero fue colector de la ayuda de Tudela en 1364-65, en unión del canónigo Guillem de Meaucort, el judío Ezmel de Ablitas y Gutier García de Aguilar (que en 1366 fue tasado en 14 f.) (P. AZCÁRATE, Un ejemplo de contribución extraordinaria, citado en nota 3; p. 23, nota 38).

${ }_{102} \mathrm{~J}$. ZABAlo, Participación navarra en la guerra de los dos Pedros. La expedición a Murviedro, nota 4.

${ }^{103}$ J. Baleztena, Catálogo de Comptos. Papeles sueltos, doc. 625 y 630. 
1. Pascual Falcón (Santa María, núm. 19). Es uno de los tudelanos que tuvo que contribuir con $15 \mathrm{fl}$. en 1363 al préstamo forzoso tantas veces aludido ${ }^{114}$.

2. Bartolomé de la Flota (San Jorge, núm. 13). Recuérdese que una Elvira de la Flota contribuyó con $14 \mathrm{fl}$., y un Juan de Flotas fue tasado en 10 florines.

3. Juan de Fustiñana (San Salvador, núm. 50). Sabemos que realizó préstamos a particulares por importe de 180 libras ${ }^{103}$.

4. Pedro Sánchiz de Lérida (San Salvador, núm. 67). Sus préstamos a particulares ascendieron a la suma de 110 libras ${ }^{106}$.

\section{6 florines}

1. Fortuño de Serán (Santa María, núm. 37). Administró por cuenta de la Hacienda real el peaje de Tudela durante el segundo semestre de este año $1366 .{ }^{107}$. Tengamos presente que otros miembros del linaje cotizan sólo cinco y tres florines, respectivamente.

2. Juan del Bayo (San Salvador, núm. 37). Sus préstamos a particulares ascendieron a 134 libras ${ }^{108}$. Recuérdese que otro Bayo fue tasado en 9 florines.

\section{5 florines}

1. Martín Ros (Santa María, núm. 47). Recuérdese que a Sancho Ros se le asignó la cuota de 11 florines, pero citaremos a otro Ros que sólo pagó cuatro.

2. Jaime de Serán (Santa María, núm. 8). Remito a lo dicho sobre los Serán en la nota 107.

104 J. ZABALO, Participación navarra ... Murviedro, nota 4.

109 J. CARrasco, Propietarios judios, p. 72.

106 Id., id.

101 AGN, Comptos, reg. 119, f. 358. Ya señalé que en la edición de la lista de fuegos de 1366 el apellido Serán aparece erróneamente transcrito. La travesura de un niño de esta familia Serán, que abrió un dique de riego, provocó daños en la muralla de adobe de la morería el año 1381 (B. LEROY, Tudela, une ville, nota 19).

${ }_{108}$ J. CARRASCO, Propietarios judios, p. 72. Hacia 1393, un Juan del Bayo fue enviado a Zaragoza para aprender la talla de piedras -preciosas, se supone- durante dos años (B. LEROY, Les relations de Tudela et Saragosse au XIV siècle, Homenaje a Lacarra, "Príncipe de Viana», Anejo 3, 1986, p. 466). 
4 florines

1. Pedro Caritat (San Jaime, núm. 34). Ya dijimos que, aunque fue tasado en 14 florines, logró pasar como hidalgo y abonar sólamente cuatro (nota 81).

2. Miguel de Guerguetiáin (Santa María, núm. 20). Estaba casado con Estebanía de Beraiz. En asociación con el pamplonés García de Roncesvalles realizó un activo comercio con el exterior, como se comprueba en los Peajes de Tudela de 1365 y $1366^{109}$.

3. Bartolomé Ros (La Magdalena, núm. 42). Ya hemos citado otros Ros tasados en 11 y en 5 florines.

4. Gil de Beraiz (San Nicolás, núm. 28). Hemos citado un García de Beraiz (Veraiz) tasado en 13 florines. Sabemos que un Pedro de Beraiz era notario de Tudela en $1393^{110}$.

5. Martín de Verde (La Magdalena, núm. 52). Un homónimo aparece citado como notario en Tudela en 1393 . Hemos aludido a otro Verde tasado en 10 florines"'.

6. Pedro Jiménez de Verde (Santa María, núm. 13). Recuérdese que un Pascual Jiménez de Verde fue tasado en 12 florines.

Habría que añadir aquí a aquéllos que en realidad parece que pagaron sólo 4 florines aunque habían sido tasados en cantidades superiores, como Pedro Iñiguez de Ujué y Pedro de Ainsa (ambos en 14 fl.), y Martín González de Morentin (en 13 fl.)

\section{3 florines}

1. Juan de Eslava (San Jorge, núm. 31). Aunque se le había asignado en principio una cuota de 12 florines -síntoma de su próspera situación económica- en realidad consiguió contribuir sólo con tres, pasando por hidalgo ${ }^{112}$.

2. María Jiménez de Ainsa (San Jaime, núm. 45). Sorprende también esta escasa cuota, pues los Jiménez de Ainsa pertenecen a la burguesía de los negocios, y se hallaban emparentados con los Caritat y los Arnalt de Ujué, según hemos visto al tratar del Pedro de Ainsa que había sido tasado en 14 florines.

109 J. ZABALO, Peaje de Tudela de 1365, nota 28. B. LeROY, Les villes dans le monde ibérique, p. 50. 730.

110 B. LEROY, Tudela en 1381-83 à travers le registre du notaire Martin don Costal, p. 88.

111 Id., id.

112 J. CARRASCO, La población, p. 413, n. ${ }^{\circ} 11$; p. 424, n. ${ }^{\circ} 9$. Ver sobre los Eslava la nota 
3. Pedro Jiménez don Bernalt (San Salvador, núm. 66). También sorprende esta cuota, cuando sabemos que un Juan Jiménez don Bernalt realizó préstamos a particulares por importe de 146 libras"."

4. Belenguera de Serán (Santa María, núm. 22). Hemos citado otros miembros de este linaje con cuotas de cinco y seis florines.

Habría que incluir aquí a Gracia de Sesa -o Sesma, si identificamos ambos patronímicos- que, aunque tasada en $8 \mathrm{fl}$., en realidad desembolsó sólo tres.

\section{2'5 florines}

1. Martín don Costal (San Julián, núm. 37). Podemos sospechar que cotizó por debajo de sus posibilidades el que más tarde aparece como notario, actividad que debía ser bastante rentable ${ }^{114}$.

2. Pedro Pastor (San Julián, n. 35 ). No podemos asegurar que sea pariente del Juan Pastor tasado en 14 florines, pero no descartamos en absoluto esa eventualidad.

\section{2 florines}

1. Fernando de Araciel (San Jorge, núm. 14). Aunque tasado en $10 \mathrm{fl}$., en realidad pagó sólo 2 como hidalgo"s.

\section{1 's florines}

1. Juana Renalt (San Julián, núm. 43). Ciertamente, no nos consta que pertenezca al mismo tronco familiar que los Renalt que pagaron respectivamente 14,10 y 8 florines. Puede tratarse también de un pariente pobre de ese linaje.

Si recapitulamos los datos que hemos analizado hasta aquí sobre la contribución efectiva -no la teórica- de las familias más o menos relevantes de la burguesía de Tudela, resultaría el siguiente cuadro numérico:

113 J. Carrasco, Propietarios judios, p. 72.

114 B. LEROY, Tudela en 1381-83 à travers le registre du notaire Martin don Costal, p. 723-739.

i1) J. Carrasco, La población, p. 413, n. 10; p. 424, n.. 14. 


\section{CUADRO VII}

\begin{tabular}{ccc} 
Florines & Fuegos & $\begin{array}{c}\text { Total } \\
\text { Florines }\end{array}$ \\
\hline 14 & 6 & 84 \\
13 & 1 & 13 \\
12 & 2 & 24 \\
11 & 5 & 55 \\
10 & 11 & 110 \\
9 & 6 & 54 \\
8 & 11 & 88 \\
7 & 4 & 28 \\
6 & 2 & 12 \\
5 & 2 & 10 \\
4 & 9 & 36 \\
3 & 5 & 15 \\
$2 ' 5$ & 2 & 5 \\
2 & 1 & 2 \\
$1 ' 5$ & 1 & $1 ' 5$ \\
\hline TOTAL & 68 & $537 ' 5$
\end{tabular}

El promedio resultante de estos 68 vecinos conocidos y supuestamente destacados de Tudela es de 7'9 florines por fuego, netamente superior -en proporción de 2'6 a 1- al de las 33 familias relevantes de Pamplona, que no pasaba de 2'97 florines.

En verdad, tampoco en la ciudad del Ebro faltaron casos de burgueses acaudalados que -haciéndose pasar como hidalgos- consiguieron zafarse con cuotas bajas, según hemos ido viendo; pero, en su conjunto, es evidente que la burguesía tudelana se comportó en la ayuda de 1366 de manera bastante más honorable que la pamplonesa. Las razones por las que en Tudela se asignaron cuotas tan variadas -hasta los $14 \mathrm{fl}$.-, rebasando tan generosamente las previstas por la normativa oficial, no se explican en la documentación y se nos escapan por completo. En cuanto al caso particular de los jurados, dado que el censo de Tudela no los identifica -y eran ocho- desconocemos qué cuotas se autoasignaron.

Tampoco sabemos si este llamativo y sorprendente contraste entre las escalas contributivas de ambas ciudades se limitó al año 1366 o se repitió en ocasiones semejantes, pues no se ha conservado documentación al respecto, e incluso falta para Tudela y toda su merindad la correspondiente a la ayuda del año 1427. 
En cuanto a las diferencias que podríamos llamar estructurales entre ambas burguesías, me atrevo a sugerir la siguiente hipótesis. La de Pamplona parece más cerrada y exclusivista, con un núcleo de rancios linajes estrechamente vinculados entre sí y una tendencia a la endogamia más acusada que la de Tudela. Cabe imaginarla también más celosa de su abolengo, de su corporativismo y de su predominio en la vida social y económica de la capital. Más cohesionada internamente que la tudelana, imaginamos que posee una conciencia más viva de su condición de minoría oligárquica. Por ello, es capaz de ejercer con más firmeza el control del municipio, y consigue defender con más efectividad sus intereses como grupo dominante a escala local.

En cuanto a las relaciones -familiares y de negocios- entre ambas burguesías, parecen más bien escasas, pues cada una se mueve generalmente en su propio ámbito. Pero ésta y otras cuestiones semejantes no podemos tratarlas aquí y deben quedar para mejor ocasión.

\section{RÉSUMÉ}

Parmi la mince série de dénombrements fiscaux en Navarre au Moyen Age, le Libro de fuegos de 1366 (Livre des Us et Coutumes de 1366), par le seul fait qu'il enregistre aussi bien les noms des têtes de famille que la quotité qui était assignée à chacune d'elles, est l'unique texte qui nous permet d'étudier, avec quelques détails, la façon dont contribuèrent, à cette époque, les habitants des deux principales villes du royaume: Pamplona et Tudela.

La minutieuse révision du manuscrit original -que la transcription, publiée par J. Carrasco en 1973, nous a permis d'étudier à fond-en même temps que l'information complémentaire obtenue à partir d'autres sources, nous permet de déboucher sur de surprenantes conclusions: les 33 familles de la haute bourgeoisie de Pamplona payèrent une moyenne de 3 florins à peine, tandis que la moyenne des 68 noms les plus connus de Tudela intervinrent, eux, pour 8 florins. Nous ne savons pas les raisons de cette claironnante différence, les familles de Tudela dépassant largement la moyenne -prévue pour l'ensemble du royaume- de 2,5 florins par famille, pas plus que nous ne connaissons les raisons pour lesquelles, à Tudela, on ne respecta pas les quatre niveaux de cotisation (quotité) ( $1,2,3$ et 4 florins) que les normes royales avaient établis cette année-là.

\section{SUMMARY}

The Libro de fuegos de 1366 (The Book on Habits and Customs of 1366) is the only text that allows us to study, in details, the way in which the inhabitants of the two main cities of the realm, Pamplona and Tudela, used to contribute in the tax system. 
Among a very reduced series of fiscal censuses in Navarra during the Middle Ages, this book is quite unique because it registers both the name of the heads of family and the quota asigned to each one.

The meticulous revision of the original manuscript, which transcription by J. Carrasco in 1973 helped us to study it in detail -as well as complementary information obtained through other sources allows us to find surprising conclusions. One of them is that the 33 families of the high bourgeoisie in Pamplona paid, on an average, scarcely 3 florins while the average of the 68 most famous lineages in Tudela contributed with 8 florins. We do not know the reasons for this important difference, Tudela's families exceed largely the average of 2,5 florins per family, foreseen for the realm as a whole. We also ignore the reasons why, in Tudela, the four levels of quota (1, 2, 3 and 4 florins) established for that peculiar year by royal norms are not respected. 